\title{
ONOMASTICON OTTOMANICUM III : KÖPRÜLÜ, UN ASSEZ JOLI NOM D'EMPRUNT
}

Olivier Bouquet

\author{
Belin | « Revue d’histoire moderne \& contemporaine »
}

2013/2 n 60-2 | pages 58 à 86

ISSN 0048-8003

ISBN 9782701181035

Article disponible en ligne à l'adresse :

https://www.cairn.info/revue-d-histoire-moderne-etcontemporaine-2013-2-page-58.htm

Distribution électronique Cairn.info pour Belin.

(C) Belin. Tous droits réservés pour tous pays.

La reproduction ou représentation de cet article, notamment par photocopie, n'est autorisée que dans les limites des conditions générales d'utilisation du site ou, le cas échéant, des conditions générales de la licence souscrite par votre établissement. Toute autre reproduction ou représentation, en tout ou partie, sous quelque forme et de quelque manière que ce soit, est interdite sauf accord préalable et écrit de l'éditeur, en dehors des cas prévus par la législation en vigueur en France. Il est précisé que son stockage dans une base de données est également interdit. 


\section{Onomasticon Ottomanicum III: Köprülü, un assez joli nom d'emprunt}

Olivier BOUQUET

"Giscard d'Estaing, c'est effectivement un assez joli nom d'emprunt" (Charles de Gaulle, au sujet de son ministre des Finances ${ }^{1}$ ).

L'identification des "faux nobles", de leurs noms d'emprunt et de leurs généalogies inventées est une activité appréciée dans des régimes républicains ${ }^{2}$. Elle prend une saveur toute particulière lorsqu'elle concerne ceux qui ont exercé les plus hautes fonctions de l'État. Ce n'est a priori pas le cas de la Turquie: au lendemain de l'instauration de la République en 1923, la dynastie ottomane fut bannie du pays et les plus hauts dignitaires exclus de la scène politique; une partie d'entre eux se reconvertirent dans les affaires, les arts et les lettres; d'autres cultivèrent la mémoire de leurs ancêtres à l'ombre des résidences (konak) de la capitale déchue; de nouvelles lignées d'entrepreneurs, d'universitaires et de politiques se constituèrent. Dans un contexte officiel de tabula rasa ottomanica, les grandes familles impériales se firent d'autant plus discrètes qu'aucune noblesse d'État n'avait jamais été reconnue sous les Ottomans. Des dynasties s'étaient certes formées, identifiables par des noms d'ancêtre plus ou moins illustres. Mais les patronymes, loin d'être des "désignateurs rigides ",

1. Cité par Claude Lelièvre, Christian Nique, L'école des présidents. De Charles de Gaulle à François Mitterrand, Paris, Odile Jacob, 1995, p. 159. En référence, d'une part, au décret du 16 janvier 1923, en vertu duquel René Giscard, né le 19 février 1891 à Clermont-Ferrand, fut autorisé à modifier son patronyme en Giscard d'Estaing [Camille DE SAINT-MARC, État des personnes qui ont fait modifier leur nom patronymique par addition, substitution ou autrement (décrets de 1901 à 1930), Paris, Librairie historique et nobiliaire Georges-Saffroy, 1937, p. 119], et d'autre part, à l'emprunt levé par son neveu, Valéry Giscard d'Estaing, ministre des Finances, en 1962.

2. Plusieurs collègues sont intervenus dans la préparation de cet article: Sinan Kuneralp m'a aidé à obtenir d'importants documents; Şevket Yıldız et Nuri Sağlam m'ont apporté leur concours bibliographique; Işı Tamdoğan est l'auteure des photographies prises au mausolée des Köprülü; Güneş Işıksel et Nicolas Vatin ont vérifié certaines de mes traductions; Marc Aymes et Jean-Frédéric Vernier ont lu une première version du texte. Je les remercie tous chaleureusement pour leur aide précieuse.

3. S. Kripke cité par Pascal EngeL, Identité et Référence. La théorie des noms propres chez Frege et Kripke, Paris, Presses de l’École normale supérieure, 1985, p. 82-88. 
variaient au contact d'institutions onomastiques multiples et changeaient à chaque génération. Les lignées distinguées par le service du sultan ne songeaient guère à transmettre des titres, à se constituer des blasons, ou à défendre la gloire d'un nom contre usurpateurs de lignage et falsificateurs de généalogie ${ }^{4}$.

Aussi, quand au cours d'une promenade sur les rives du Bosphore, à l'approche d'un de ces konak de grande famille, un ami érudit me confia que le célèbre universitaire turc, Mehmed Fuad Köprülü (1890-1966), connu et reconnu comme descendant des célèbres grands vizirs Köprülü (seconde moitié du XVII ${ }^{\mathrm{e}}$ siècle-début du XVIII ${ }^{\mathrm{e}}$ siècle), non seulement n'était pas issu de cette prestigieuse lignée, mais qu'il ne fallait surtout pas le répéter, je m'étonnais autant d'une telle révélation que du non-dit dans lequel il importait de la maintenir. J'avais jusqu'alors pensé que les descendants de pachas avaient toujours évité de rappeler leurs origines, et que les cas d'appropriation valorisante de figures historiques s'en tenaient aux héros de la Guerre d'indépendance (1919-1922). Mais à l'occasion de recherches ultérieures, je mesurais qu'un changement s'était produit dans les années 1980: en quête de portraits de dignitaires, les descendants s'étaient mis à chiner chez les brocanteurs; dans les dîners en ville, des personnes en vue se prêtaient des origines impériales. Cet ami m'avait ainsi raconté que l'épouse d'un des hommes d'État les plus importants du pays tirait gloire d'être la petite-fille d'une employée du Palais (saraylı), certes de fonction modeste puisque lavandière, mais qu'avec le passage des ans, c'était à peine si l'aïeule n'était pas devenue sultane. À l'évidence, les grandes familles se souciaient davantage de leur grandeur perdue, de la distinction que la société environnante semblait désormais leur reconnaître, autant que des institutions islamiques dont leurs ancêtres avaient été les fondateurs. Il était même des cas particuliers de "guérilla mondaine " 5 entre branches rivales qui se disputaient la descendance de tel pacha renommé ou de tel vizir illustre. Ainsi en allait-il des Köprülü.

La loi de 1934 sur les noms propres (dont le présent dossier examine la portée) institua l'obligation des noms de famille. Elle joua un rôle de fixateur anthroponymique officiel à l'usage des citoyens turcs dans leur ensemble. Elle fit passer à la trappe de nombreux noms impériaux. Mais elle valida l'usage multiséculaire du nom Köprülü. La raison en était que le patronyme était répandu hors de la seule lignée des grands vizirs. Il le resta dans le demi-siècle

4. Ces remarques sont inspirées de quelques-uns de mes précédents travaux: «Old elites in a new republic: the reconversion of Ottoman bureaucratic families in Turkey (1909-1939)", Comparative Studies in South Asia, Africa and the Middle East, 31-3, Fall 2011, p. 588-600; "Généalogies impériales en République : le cas de la Turquie", Revue d'histoire moderne et contemporaine, 58-2, 2011, p. 146-179; «Onomasticon Ottomanicum: identification administrative et désignation sociale dans l'État ottoman du XIX" siècle", Revue des mondes musulmans et de la Méditerranée, 127, juillet 2010, p. 213-234; "Onomasticon Ottomanicum II. Le voile de l'identité", in Nathalie CLAYER, Erdal KAYNAR (éd.), Penser, agir et vivre dans l'Empire ottoman et en Turquie, Louvain, Peeters, 2012, p. 283-306.

5. Tiphaine BARThÉlemy, «Noms patronymiques et noms de terre dans la noblesse française (XVIII $-\mathrm{XX}^{\mathrm{e}}$ siècles)", in Guy Brunet, Pierre DARLu et Gianna ZEI (éd.), Le patronyme. Histoire, anthropologie, société, Paris, Éditions CNRS, 2001, p. 61-79. 


\section{DOCUMENT 1}

La Bibliothèque Köprülü

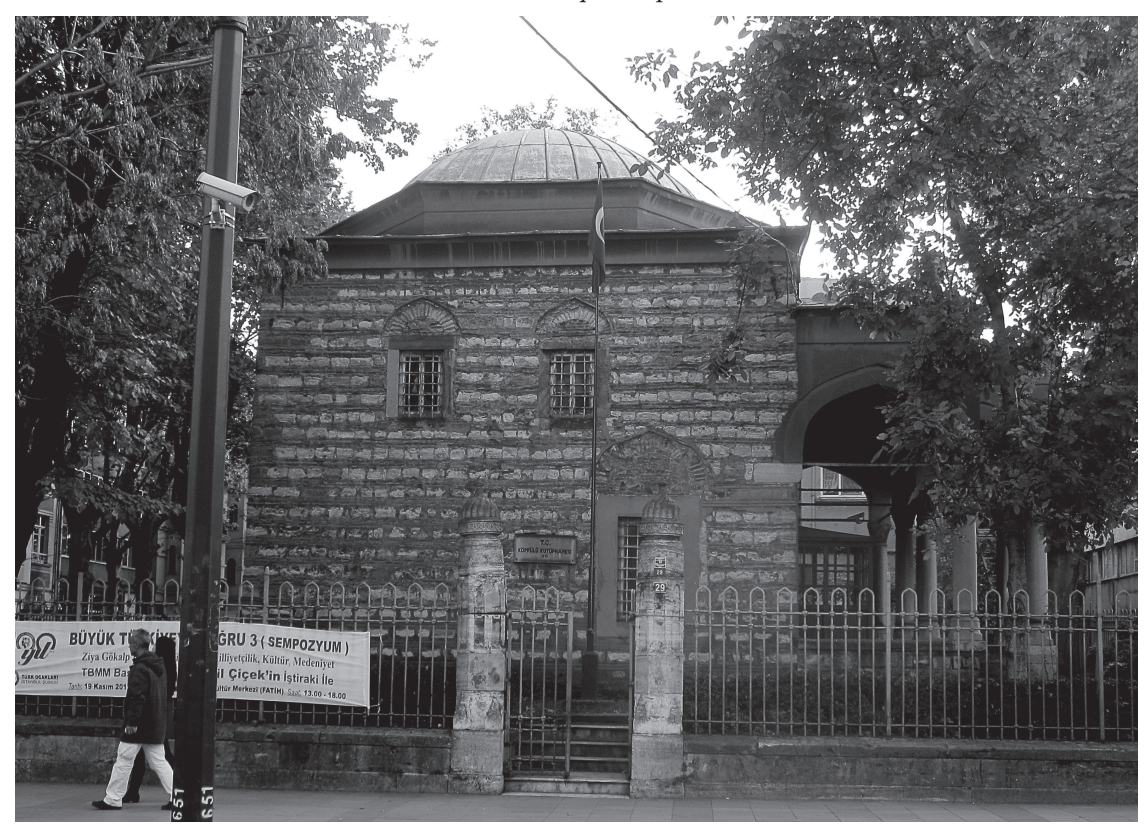

suivant, au point qu'aucun de ceux qui le portaient ne semblait y attacher le moindre prix ou n'en tirer fierté. Que ce nom de famille, à la fin du XX $\mathrm{X}^{\mathrm{e}}$ siècle, en vînt à cristalliser une idéologie nobiliaire dont étaient exempts l'Empire ottoman finissant et la Turquie kémaliste, et que l'historien le plus important du pays, Mehmed Fuad Köprülü, fût soupçonné d'avoir usurpé un nom qui n'avait fait l'objet d'aucune défense dans l'Empire de ses ancêtres: tel est le double paradoxe que cet article vise à éclairer.

\section{LA GLOIRE DU NOM : LE MAUSOLÉE DES KÖPRÜLÜ}

Istanbul est la ville des cimetières. Les Ottomans avaient le souci de leur dernière demeure. Istanbul est la ville des pachas. L'une de ses artères centrales, la Divanyolu, abrite le mausolée de deux des plus illustres d'entre eux, Mehmed Köprülü Pacha et son fils Ahmet Fazıl Pacha. Ces puissants grands vizirs de la seconde moitié du XVII ${ }^{\mathrm{e}}$ siècle veillèrent à se réserver le meilleur des emplacements funéraires: le mausolée est stratégiquement placé dans le quartier de Çemberlitaş, dans l'un des centres historiques de la capitale, entre Topkap1 et Beyazit. Niché au cœur d'un complexe dynastique (külliye) dont les Köprülü furent les fondateurs, il est situé à proximité d'une prestigieuse bibliothèque qui porte encore leur nom. 


\section{DOCUMENT 2}

Les inscriptions funéraires des Köprülü, père et fils

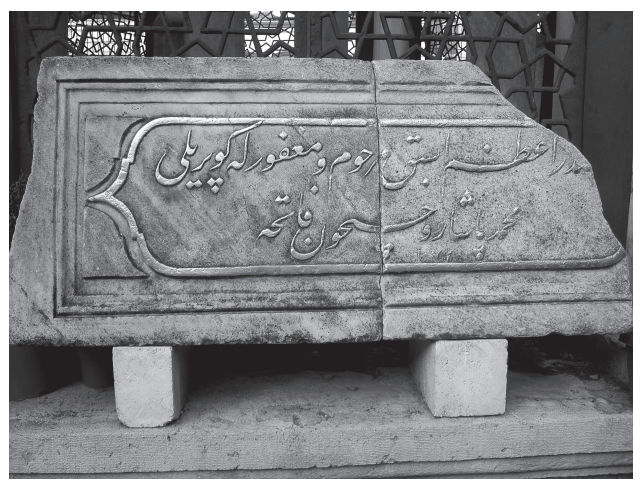

«Sadr-ı esbak merhum ve mağfurle Köprülü Mehmed Paşa rühu içün fatiha»

«La fatiha pour l'âme de l'ancien grand vizir Köprülü Mehmed Pacha, celui qui jouit de la miséricorde et du pardon"

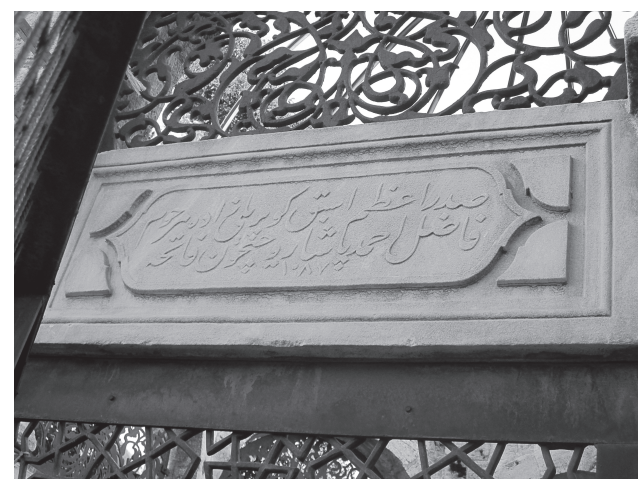

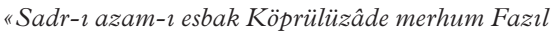
Ahmed Paşa rühu içün fatiha»

«La fatiha pour l'âme de l'ancien grand vizir, Köprülüzâde Fazıl Ahmed Pacha, qui jouit de la miséricorde»

Dans la cour du complexe sont regroupées les tombes du fondateur éponyme de la dynastie, Mehmed Pacha, de son fils, Ahmed Fazıl Pacha, et de son épouse, Ayşe Hanım ${ }^{6}$. Les stèles sont anépigraphes ${ }^{7}$, mais deux inscriptions (kitabe) placées à l'entrée du mausolée signalent clairement l'identité des inhumés.

Père et fils furent tous deux grands vizirs: voici un premier trait distinctif des Köprülü. Cette très grande famille ottomane en réunit d'autres qui la constituent en contre-exemple inégalé d'un système politique qui ne reconnaissait aucune noblesse d'État: qu'un dignitaire ait occupé l'insigne fonction directement après son père, et ce pendant quinze ans, que deux de ses fils lui aient succédé, qu'au total six membres de la famille aient été grands vizirs - 38 ans en un peu plus d'un demi-siècle, entre 1656 et 1710 -, voilà qui n'était jamais arrivé dans l'histoire de l'Empire, voilà qui ne s'est jamais reproduit. La dynastie des Köprülü atteignit un tel prestige, qu'en 1732 l'un de ses membres, Ahmet Pacha (arrière-petit-fils du fondateur éponyme), alla jusqu'à commander une chronique à la gloire de «la lignée des vizirs» (silsile-i vezaret). C’était une première: sous la glorieuse protection de la "dynastie d'Osman" (hanedan Al-i Osman), le seul lignage qui ait jamais fait l'objet d'un tel récit, le chroniqueur prit

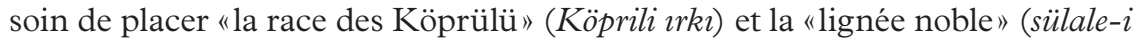

6. Ahmed Vefa ÇoBanoĞLU, "Köprülü Külliyesi», Türkiye Diyanet Vakfı İslam Ansiklopedisi (dorénavant DYA), 26, Ankara, Diyanet Vakf1, 2002, p. 255-257, p. 256.

7. On observe des cas similaires dans d'autres cimetières de famille (Jean-Louis BACQUÉ-GRAMMOnt, Hans-Peter Laqueur, Nicolas VAtin, Stelae Turcicae II. Cimetières de la mosquée de Sokollu Mehmed Paşa à Kadırga Limam, de Bostancı Ali et du türbe de Sokollu Mehmed Paşa à Eyüb, Tübingen, Ernst Wasmuth Verlag, 1990, p. 45). 


\section{DOCUMENT 3}

La visite au mausolée des Köprülü

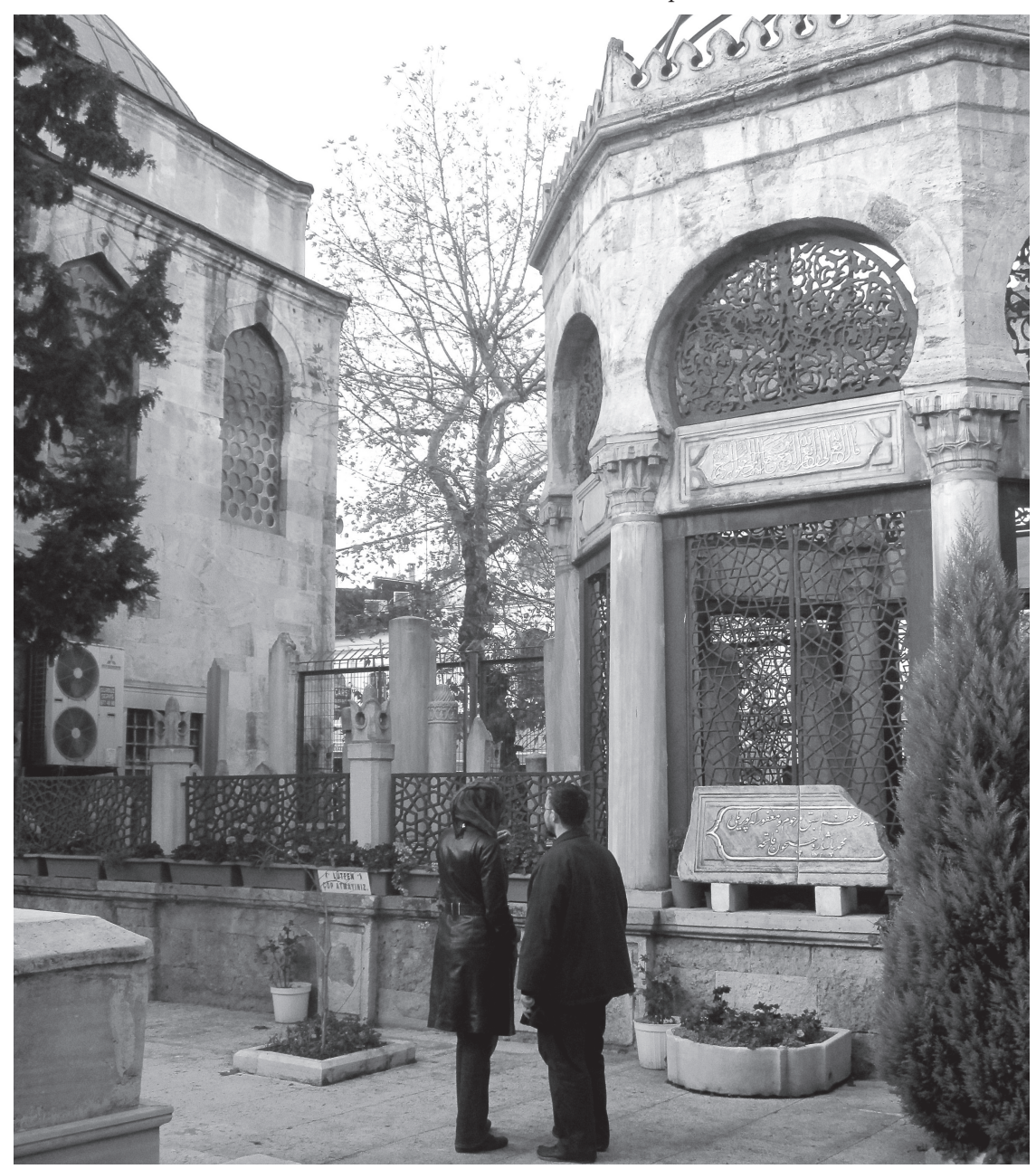

pak) dont il devait retracer l'histoire et louer les retentissantes actions ${ }^{8}$. La gloire des Köprülü fut entretenue par les historiographes suivants, à telle enseigne qu'à la toute fin de l'Empire, un observateur notait qu'ils occupaient encore

8. Cette chronique fut rédigée par Behçetî İsmaîl Efendi, à la demande de Köprülüzâde Ahmed Pacha, entre 1732 et 1738. Conservée à la Bibliothèque Köprülü (manuscrit 212, section Ahmed Pacha), elle a récemment fait l'objet d'une transcription (Mehmet Fatih GöKÇEK, "Behcetî Seyyid İbrahim Efendi "Târîh-i Sülale-i Köprülü” (transkripsyon ve tahlil)", thèse de licence supérieure, Université de Marmara, 2006). Les expressions citées en italiques sont extraites du texte de cette chronique (ibidem, p. 2). 


\section{DOCUMENT 4}

L'indication du mausolée en caractères latins

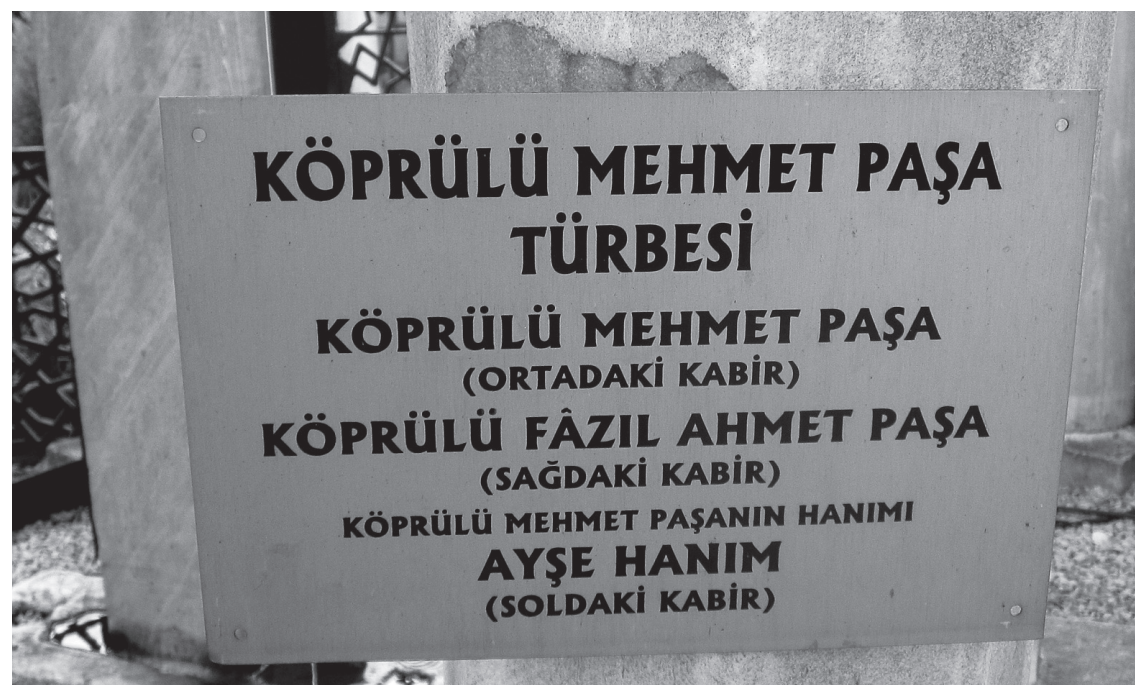

«un lieu de consécration dans le cœur des gens $»^{9}$. Alors que plus près de nous l'imaginaire des modernes s'ancrait davantage dans les règnes des sultans que dans les rythmes de la Sublime Porte, des ottomanistes parlaient du temps que ces grands vizirs avaient marqué de leur sceau comme des "années Köprülü » ${ }^{10}$.

Le régime officiel turc voyait les choses d'un œil différent: les grandes familles ottomanes furent clouées au pilori de l'idéologie méritocratique kémaliste, et les noms de leurs membres furent peu à peu oubliés. Le cimetière de famille n'accueillit plus aucune dépouille. Après l'introduction de l'alphabet latin en 1928, les visiteurs du mausolée n'étaient plus aussi nombreux à pouvoir déchiffrer les épitaphes, afin de prononcer selon l'usage la fatiha, bénédiction propitiatoire destinée à l'âme des défunts.

Le complexe islamique continuait d'être néanmoins en activité, les fonds de la bibliothèque utilisés, et le cimetière visité. Des pancartes en caractères latins furent ajoutées pour entretenir la mémoire des fondateurs.

Un jour d'été 1966, ces pancartes furent lues plus qu'à l'accoutumée. Un dernier descendant était inhumé dans le cimetière. Le plus étonnant dans l'histoire est qu'il s'agissait d'un des grands hommes de la République: Mehmed Fuad Köprülü.

9. Martin Hartmann, Dichter der neuen Türkei, Berlin, Urkunden und Untersuchungen zur Geistesentwicklung des heutigen Orients, 1919, p. 91 (je traduis de l'allemand).

10. Metin KUnT, «The Köprülü years, 1656-1661», Ph.D., Princeton University, 1972. 


\section{LA MORT DU PROFESSEUR}

Le $1^{\text {er }}$ juillet 1966, une cérémonie funéraire a lieu à la Mosquée de Beyazit, puis, à deux pas, dans la cour de l'Université d'Istanbul. Il y a foule. Les plus hautes autorités de l'État et du monde universitaire sont représentées en la personne du Secrétaire général du Premier ministre, accompagné d'un ministre d'État, et flanqué des hauts responsables de la Préfecture, de la Mairie et de l'Université. Tous sont venus rendre hommage à Mehmed Fuad Köprülü, ancien ministre et professeur émérite d'histoire littéraire de l'Université d'Istanbul. Sa dépouille est inhumée dans la cour du mausolée des Köprülü, non loin de la maison où il naquit en $1890^{11}$. Les autorisations d'inhumation intra muros font l'objet de dérogations accordées à titre exceptionnel. Au plus célèbre des Köprülü, la République rend les honneurs.

Avec la disparition de Fuad Köprülü, la Turquie perd son professeur ${ }^{12}$. Le défunt est sans nul doute l'historien le plus important du pays. Sa carrière aura été aussi époustouflante que précoce. À chaque étape, il a vingt ans d'avance. Titulaire de la chaire de littérature turque de la Faculté de lettres à l'âge de 23 ans, il devient doyen de cette faculté dix ans plus tard. Il est au cœur de l'institutionnalisation universitaire républicaine, comme fondateur, en 1924, de l'Institut de Turcologie (Türkiyat Enstitüsü) dont il dirige la revue (Türkiyat Mecmuası). Sa réputation de chercheur franchit les limites du pays: au sortir de la Première Guerre mondiale, un observateur allemand le repère comme l'une des vingt-cinq personnalités amenées à compter dans la Turquie de demain, non seulement comme poète mais comme homme de sciences ${ }^{13}$. Ses œuvres font l'objet de comptes rendus les années suivantes ${ }^{14}$. Il enchaîne les distinctions: membre de l'Académie soviétique scientifique en 1925, de l'Académie scientifique de Hongrie en 1926, Docteur honoris causa de l'Université de Heidelberg en 1927. La presse turque a vite fait d'honorer ce «jeune» de trente-cinq ans, déjà «grand» au point de jouir d'une "réputation internationale ${ }^{15}$. En 1929, il est déjà professeur émérite. En mars-avril 1935, il est le premier professeur invité à prononcer, au Centre d'études turques de la Sorbonne inauguré quelques semaines plus tôt, trois conférences retentissantes dont il fait la synthèse dans un livre salué par les historiens des Annales $^{16}$. Il a déjà un pied dans la politique, lorsqu'il est élu

11. Milliyet, 2 juillet 1966, p. 1 (http://gazetearsivi.milliyet.com.tr/Arsiv/1966/07/02; consulté le 10 décembre 2011).

12. "La France perd son prof", Libération, 749, 18 octobre 1983 (hommage à Raymond Aron).

13. M. HaRTMAnn, Dichter..., op. cit., p. 91.

14. Voir, par exemple, Lucien BoUvat, "Les premiers mystiques dans la littérature turque», Revue du monde musulman, 43, février 1921, p. 236-266.

15. "Türk gençleri yaşayan büyüklerinizi tanıyınız: otuz beş yaşında beynelmilel bir şöhret kazanan Köprülüzâde Mehmed Fuad Bey'in hayat1", Resimli Perşembe, 161, 21 Haziran 1928, p. 6 (cité par Ömer Faruk AKÜN, "Mehmed Fuad Köprülü», DYA, 28, 2003, p. 471-486, p. 486; je traduis du turc). Voir également M. Hanefi PAlabiyık, Ord. Prof. Dr. M. Fuad Köprülü’nün İlmî Hayatı ve Tarihçiliği, Ankara, Akçag, 2005, p. 104-1.

16. Les origines de l'Empire ottoman, Paris, E. de Boccard, 1935; compte rendu de Lucien FebVRE, Annales d'histoire économique et sociale, 9, 1937, p. 100-101. On trouvera des éléments sur le rôle qu'il 
député en 1935. Mais il continue de publier activement, avant de s'engager, après la Seconde Guerre mondiale, comme fondateur du Parti démocratique en 1946, et ministre des Affaires étrangères (mai 1950-avril 1955).

Dans les publications qui font suite à sa mort, le très regretté est présenté rien moins que comme «le monument de la science turque ${ }^{17}$ ". Ses collègues déplorent une "perte douloureuse ${ }^{18}$, et des revues scientifiques étrangères d'importance saluent sa mémoire. Au cours des années qui suivent, les commémorations et les hommages se succèdent, en plus du numéro spécial qui lui est naturellement consacré dans la revue dont il fut le fondateur et où il est célébré comme le «maître disparu» ("Merhum Üstâd» ${ }^{19}$ ). Au-delà de sa spécialité, le grand érudit figure même comme un «pionnier de la modernisation turque», pour reprendre le titre d'une thèse récente qui lui est consacrée ${ }^{20}$. Au fil des ans est régulièrement étoffée et actualisée la bibliographie de «l'un des fondateurs de l'histoire moderne de la Turquie", ainsi que le désigne l'un de ses disciples, H. İnalc1k, pape actuel des études ottomanes, sans doute le seul universitaire à avoir atteint, depuis, une importance comparable dans le paysage des sciences humaines turques ${ }^{21}$.

\section{LA STÈLE OTTOMANE D'UN HOMME DU RÉGIME}

Il ne faut pas longtemps au visiteur du mausolée des Köprülü pour localiser la tombe du professeur (voir document 5.1, page suivante). Sa forme d'ensemble correspond parfaitement à celles qu'on trouve dans les cimetières intra muros: elle est notamment dotée d'une double stèle (l'une de tête, sur la gauche de la photographie, l'autre de pied, sur la droite). Plus étonnante est l'épitaphe, gravée

joua dans la rencontre historiographique entre Istanbul et Paris dans Halil İNALCIK, "The impact of the Annales School on Ottoman studies and the new findings", Review: a journal of the Fernand Braudel Center, Binghmanton, 1-3/4, 1978, p. 69-96.

17. Osman TuRAN, "Türk ilminin âbidesi : Prof. Fuad Köprülü», Türk Kültürü, 4-47, septembre 1966, p. 936-942.

18. Fevziye Abdullah TAnsel, «Memleketimizin acı kaybı: Prof. Dr. Fuad Köprülü», octobre 1966, TTK Belleten, 30-120, p. 621-636. Voir aussi Jules NÉMETH, «Kôprülüzâde Mehmed Fuat, 1890-1966», Acta Orientalia Academiae Scientiarum Hungaricae, 20, 1967, p. 365-366.

19. Türkiyat Mecmuası, 15, 1968.

20. Abdülkerim Asılsoy, «Türk modernleşmesi öncülerinden Fuat Köprülü: hayatı, eserleri ve fikirleri", Thèse, Université de Marmara, 2008.

21. Halil İNALCIK, "Türkiye'de osmanlı araștırmaları: Türkiye'de modern tarihciliğin kurucuları», TTK Bildiriler, 13, 2002, p. 101-122. Mehmed Fuad KÖPRÜLÜ a participé à des entreprises internationales d'envergure telle l'Encyclopédie de l'islam ( $2^{\mathrm{e}}$ édition), en tant que membre du comité de direction; ses publications ont fait l'objet de traductions et d'études à l'étranger. On doit à Gary Leiser d'avoir traduit plusieurs de ses œuvres en anglais, notamment The Origins of the Ottoman Empire, Albany, State University of New York, 1992; Mehmed Fuad KöPRÜLÜ et Robert DANKOFF, Early Mystics in Turkish Literature, Londres, Routledge, 2006; pour d'autres références bibliographiques, voir ibidem, p. 414415. Voir également George Thomas PARK, "The life and writing of M. Fuad Koprülü: the intellectual and Turkish cultural modernization", Ph.D., The Johns Hopkins University, 1975; Şevket YILDIZ, "Mehmed Fuad Köprülü (1890-1966)", in Jaume Aurell, Julia Pavon (ed.), Rewriting the Middle Ages in the Twentieth Century, Vol. 2: National Traditions, Turnhout, Brepols Publishers, 2009, p. 485-514. 


\section{DOCUMENT 5}

La tombe de Mehmed Fuad Köprülü
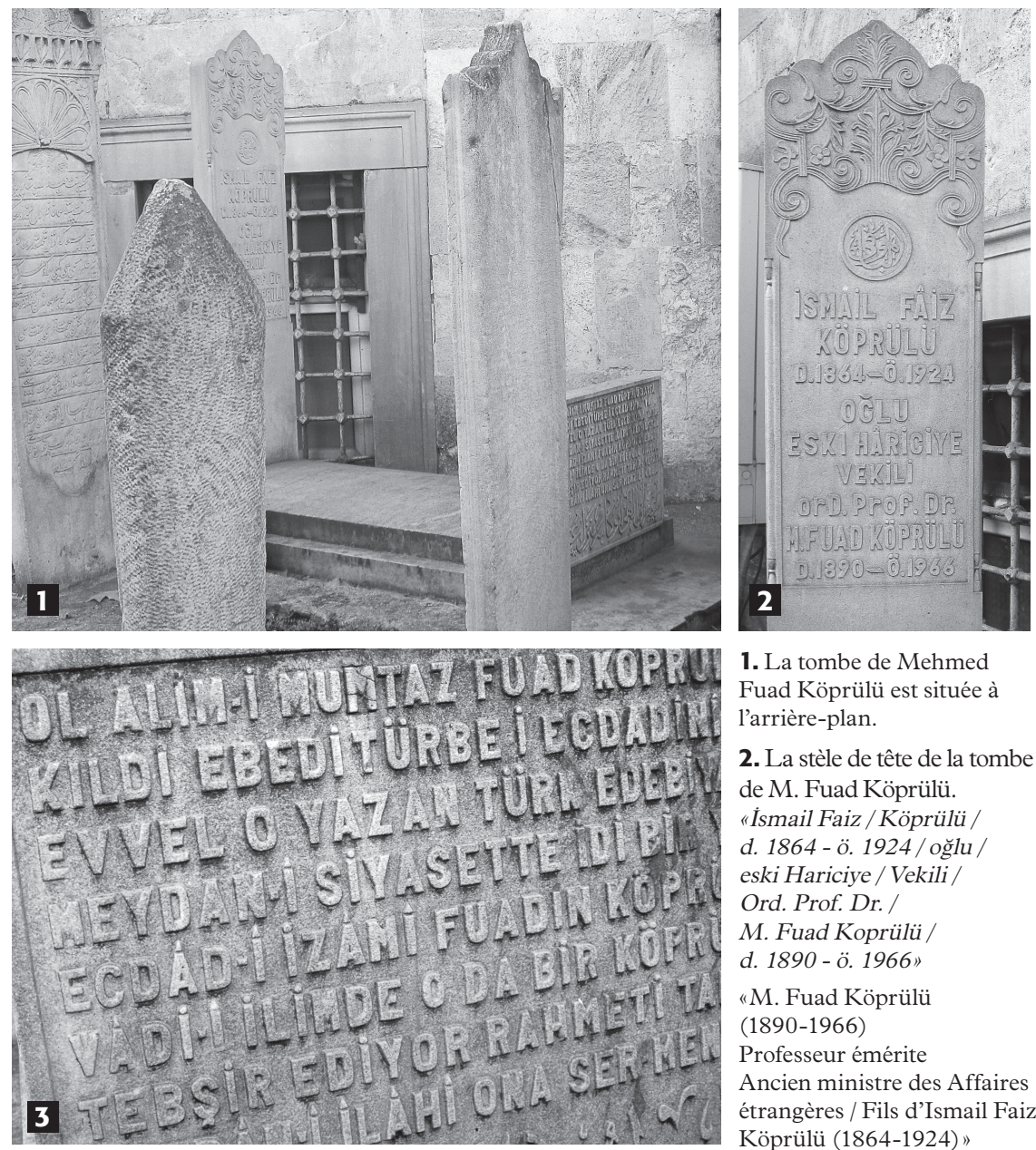

1. La tombe de Mehmed Fuad Köprülü est située à l'arrière-plan.

2. La stèle de tête de la tombe de M. Fuad Köprülü. «İsmail Faiz / Köprülü / d. 1864 - ö. 1924 / oğlu/ eski Hariciye / Vekili / Ord. Prof. Dr. / M. Fuad Koprülü / d. 1890 - ӧ. 1966" «M. Fuad Köprülü (1890-1966)

Professeur émérite

Ancien ministre des Affaires étrangères / Fils d'Ismail Faiz Köprülü (1864-1924)»

3. La stèle de pied de la tombe de $M$. Fuad Köprülü.

"Ol alim-i mümtaz Fuad Köprülï Hayfâ / «Fuad Köprülü, ce savant éminent, hélas!

Kıldı edebi türbe i ecdadini me'vâ / Il a fait du mausolée littéraire de ses ancêtres, sa demeure littéraire. Evvel o yazan Türk edebiyatına tarih / Auparavant, il avait écrit l'histoire de la littérature turque. Meydan-i siyasette idi bir yed-i beyza* / Dans le domaine politique, il était une main toute blanche. Ecdad-i izami Fuadın Köprülülerdendi / Les ancêtres glorieux de Fuad étaient les Koprülü.

Vadi-i ilimde o da bir Köprülü Hakka / Dans la vallée de la science, celui-ci aussi est un Köprülü en vérité. Tebşir ediyor rahmeti tarih $i$ vefaati / La date de sa mort annonce l'heureuse nouvelle de la miséricorde. Gufran-i ilahi ona ser menzil i ukba"/ Que la miséricorde de Dieu soit sa dernière étape».

* «Alors Moïse jeta son bâton et voici que ce fut distinctement un serpent. Il sortit sa main et voici qu'elle apparut toute blanche aux regards» (Coran, sourate 7, 107-108, traduction Jacques BERQUE, Arles, Actes Sud, Sindbad, 1990, p. 175). Les Ottomans font usage de cette expression (de même yed-i Musa, "Main de Moïse») pour désigner la capacité miraculeuse du Prophète Moïse à rétablir le souffle de la vie (Mehmet KANAR, Osmanh Türkçesi Sözlï̆̆̈̈̈, 2, Istanbul, Say, 2009, p. 3699; Ferit DevellıŏLu, Osmanlıca-Türkçe Ansiklopedik Lûgat, Ankara, Aydın Kitabevi, 1999, p. 1157). 
en caractères latins: c'est la seule de l'enclos, et elles sont rares dans ces parties de la ville. Le document 5.2 montre ce qui est inscrit sur la stèle de tête.

Mehmed Fuad Köprülü repose comme il a été enterré, en professeur et en ministre. C'est un homme du régime, d'un régime certes laïque, mais dont la plupart des citoyens espèrent dans la vie éternelle. Sa dernière demeure se place sous le signe d'une culture funéraire islamique. À plus d'un titre, la stèle de tête frappe par son caractère ottoman, qu'il s'agisse de la décoration florale supérieure, du texte, non pas gravé mais sculpté, et de la rhétorique qu'il emprunte. La désignation professionnelle (hariciye vekili) est impériale plus qu'elle n'est républicaine: purgée dans les années en 1935 à la suite de la réforme de la langue, au profit d'une désignation plus turque (dişişleri bakanı), l'expression fut en partie réintroduite en $1952^{22}$. Mehmed Fuad ayant été ministre des Affaires étrangères entre 1950 et 1955, il aurait pu employer chacune des deux formes ${ }^{23}$. Ce goût singulier pour les désignations des anciens temps affleure davantage encore dans le texte de la stèle de pied (voir document 5.3).

Cette stèle prolonge la double identité de la précédente. Du "professeur docteur», il est précisé qu’il fut un "savant éminent» (alim-i mümtaz), spécialiste d'histoire de la littérature turque: c'était là le nom de la chaire qu'il occupait, le titre d'un de ses ouvrages, et le mode de reconnaissance employé par ses pairs ${ }^{24}$. Du ministre, il est précisé qu'il fut un serviteur de l'État intègre. Il entend ici se démarquer des hommes politiques qui furent accusés, à la suite du putsch militaire du 27 mai 1960, de ne pas avoir respecté la loi dans l'exercice de leurs fonctions, et en particulier de son successeur au poste de ministre des Affaires étrangères, Adnan Menderes, Premier ministre déchu, envoyé à l'échafaud avec deux de ses ministres. Le formulaire funéraire est poétique, ottoman, islamique. Il cite une expression coranique; il fait la part belle à des formes anciennes, pourtant exclues de la langue turque ${ }^{25}$; il est orné d'un chronogramme, chargé d'indiquer la date du décès, laquelle figure déjà dans la stèle de tête ${ }^{26}$. Il faut y voir une invitation

22. Dans l'annuaire du ministère des Affaires étrangères de 1954, le ministre Köprülü est désigné comme "dişişleri vekili» [Dişişleri Vekâleti Yıllı̆̆̆ 1953 (Eylül), Ankara, Güzel İstanbul Matbaası, 1954].

23. Remplacé par le terme turc bakan en 1935, vekil (d'origine arabe) est réintroduit dans les désignations officielles en 1952, avant d'être de nouveau banni en 1960 (Geoffrey LEWIS, The Turkish Language Reform: A Catastrophic Success, Oxford, Oxford University Press, 1999, p. 156). Je remercie E. Szurek pour ses éclaircissements à ce sujet.

24. Literarhistoriker: ainsi le désigne son collègue allemand, Franz BABINGER (Die Geschichtsschreiber der Osmanen und ihre Werke, Leipzig, Otto Harrassowitz, 1927, p. 403).

25. Notamment l'izafet persan (G. LEWIS, The Turkish..., op. cit., p. 156).

26. La dernière phrase est répétée, en ottoman. Le fonctionnement du chronogramme était fondé sur l'assignation d'une valeur numérique de 1 à 1000 à chaque lettre de l'alphabet et la rédaction d'un vers, en utilisant ces lettres en fonction de leur valeur, de manière à obtenir un total équivalent à la date de la mort. Moyennant le rétablissement d'un elif pour pouvoir lire ona, le chronogramme donne 1966. Je remercie N. Vatin qui a effectué le calcul pour moi. Sur l'usage des chronogrammes, voir Edhem ELDEM, "Notes sur les chronogrammes des stèles de Merdivenköy, Mansûr Baba et Gözcü Baba", Anatolia Moderna, 2, 1992, p. 51-58; Edith Gülçin AMBRos, "One does not speak ill of the dead - or does one? Ottoman chronograms on death", Anadolu Moderna, 9, 2000, p. 211-216. 
à un "petit jeu littéraire» (E. Eldem ${ }^{27}$ ), clin d'œil d'un spécialiste de littérature. Surtout, au-delà de l'évocation patronymique de la stèle de tête - la mention du nom du père, sans doute commémorative, participait de l'intégration funéraire du fils comme Köprülü -, l'épitaphe rattache davantage l'inhumé à ses ancêtres impériaux (ecdad, cité deux fois) et à leur nom (Köprülü, cité trois fois). Le message est simple: "celui-ci aussi est un Köprülü en vérité» (hakka). Il peut paraître étonnant qu'un haut cadre d'un régime enclin, encore au milieu des années 1960, à défendre bec et ongles l'idéologie de la tabula rasa ottomanica, rappelle ainsi le passé impérial de sa famille. Les cas pourtant existent de descendants de lignée ottomane illustrés sous la République, mais désireux, au seuil de la mort, de renouer le dialogue des vivants et des morts, et soucieux de s'inscrire dans la continuité d'une lignée connue et respectée ${ }^{28}$. Mais cela suppose que le rattachement à la lignée soit avéré. Or, en ce jour de juillet 1966 où le professeur est inhumé sous les honneurs, il est un point que personne, entre les tombes du mausolée familial, n'aurait le mauvais goût d'évoquer. Parmi ses camarades, ses collègues, ou ses disciples, ils sont certainement plusieurs à se souvenir qu'un demi-siècle plus tôt il avait été dit et écrit que ce Köprülü, en vérité, n'en était pas un.

\section{« CELUI-CI [ÉtAIT-IL] en VÉRItÉ UN KöPRÜLÜ »?}

1913. Mehmed Fuad a vingt-trois ans. Sa nomination à la chaire d'histoire de littérature turque fait grand bruit. On lui reproche son jeune âge. On lui reproche de n'avoir jamais mené à terme ses brèves études. On lui reproche de devoir son poste au soutien, en haut lieu, d'un intellectuel désormais influent et écouté, Ziya Gökalp, qui, pour sa part, occupe la chaire de sociologie, la première de Turquie, créée pour lui, la même année. L'un et l'autre ne se cachent pas d'être en grande partie des autodidactes. Les érudits stambouliotes les voient comme des parvenus. Dans cette querelle entre les anciens et les modernes, où se joue la mise en place du système universitaire turc à l'œuvre depuis une douzaine d'années, Mehmed Fuad a multiplié les occasions de faire parler de lui. Il s'en est pris régulièrement, et sans ménagement, à plusieurs savants respectés qui, à ses yeux, incarnent une arrière-garde dépassée contre laquelle il entend promouvoir ce qu'il appelle une «méthode scientifique» (ilmi usul) ${ }^{29}$. Parmi les cibles de Köprülü figure un homme de lettres distingué, enseignant de la Faculté de lettres, Faik Reşad Bey, dont il critique sévèrement les écrits ${ }^{30}$. L'intéressé en aurait été durablement affecté. Et

27. E. ELDEM, "Quelques réflexions sur les chronogrammes funéraires ottomans", in Jean-Louis Bacqué-Grammont, Aksel Tibet (éd.), Cimetières et traditions funéraires dans le monde islamique, Ankara, TTK, 1996, p. 165-170, p. 165.

28. Voir O. BOUQUET, «Le vieil homme et les tombes. Références ancestrales et mémoire lignagère dans un cimetière de famille ottoman", Oriens, 39-2, 2011, p. 331-365.

29. Nuri SAĞLAM, "Ali Emiri Efendi ile Mehmet Fuad Köprülü arasındaki münakaşalar-I», İlmî Araştırmalar, 10, 2000, p. 113-134, p. 115-120.

30. Ömer Faruk AKÜN, «Faik Reşad», DYA, 12, 1995, p. 103-109, p. 105. 
la charge de Köprülü ne serait pas complètement étrangère à la démission que le vieux professeur remet à la Faculté au cours de l'année 1913-1914. L'un de ses amis est marqué par l'événement: son nom est Ali Emiri.

Ancien employé des finances, l'homme est un de ces vieux célibataires bibliophiles qui a passé sa vie à collectionner livres et manuscrits - il aurait recueilli 18000 volumes, en tous points de l'Empire où il fut en poste, de l'Albanie au Yémen, en passant par l'Anatolie orientale ${ }^{31}$. Il est d'une érudition réputée prodigieuse. Il ne connaît initialement Mehmed Fuad que de nom. Mais il a lu ses écrits polémiques et dit ne les avoir guère appréciés. Engagé ensuite dans la publication d'un ouvrage remarquable, un dictionnaire dont il possédait l'un des derniers exemplaires existants, il a eu directement maille à partir avec Mehmed Fuad ${ }^{32}$. Ce sont assez de raisons pour qu'au fil des années son inimitié se soit muée en une haine profonde. Patiemment, il passe au scalpel les écrits du promu. Il attend son heure.

1918. Köprülüzâde Mehmed Fuad est désormais un universitaire renommé. Il vient de publier son premier grand œuvre qui fait l'objet de comptes rendus rédigés par d'éminents turcologues européens. C'est l'étoile montante de la Faculté de lettres. Ali Emiri s'emploie à en réduire durablement l'éclat. Cette même année, il fonde une revue (Osmanlı Tarih ve Edebiyat Mecmuası), tribune destinée - c'est du moins ce qu'il déclare - à détruire la réputation scientifique de Fuad Köprülü. Il a fourbi ses armes : il publie un inventaire minutieux des erreurs commises par son ennemi ${ }^{33}$. La liste est détaillée, précise. Cela ne suffit pas. Ali Emiri entend ridiculiser l'auteur - «ridicule» est d'ailleurs le titre de l'article. Il apostrophe sa cible en des termes pour le moins directs et personnels:

«Comme récemment vous ne pouviez mériter, à la faveur du talent, le ministère de l'Instruction, que rétorquiez-vous à ceux qui vous consolaient en disant "vous êtes jeune encore soyez patient” ? "Mon ancêtre Köprülüzâde Fazıl Ahmed Pacha fut grand vizir à l'âge de 22 ans. Quant à moi, à présent, j'ai deux ans de plus que lui. Le ministère de l'Instruction est-il trop pour moi?" Il est vrai qu'ainsi vos prétentions perdent toute valeur. Ne réfutons pas l'argument du monsieur. C'est un enfant. Il en meurt d'envie. Devons-nous mettre en cause les vérités de l'histoire? Cependant, non seulement vous n'êtes pas le descendant de Fazıl Ahmed Pacha, mais vous devez aussi savoir que les fonctions de l'État (memuriyetler) ne sont pas des biens d'héritage. Si mon intention était d'écrire une histoire des Kıblelizâde, la lignée (silsile) des descendants et du harem immédiat de Kibleli Mustafa Pacha, après Mustafa Pacha, en combien de branches ils se sont séparés de l'arbre généalogique, et, sur chacune d'entre elles, dans quelles familles célèbres ils auraient recruté leurs gendres, je le rendrais public. Or il ne s'agit que de vous faire connaître votre lignée. Cela suffit bien comme ça ${ }^{34}$.

31. Jean DENY, "Ali Emiri Efendi», fournal asiatique, 204, avril-juin 1924, p. 375-379, p. 376; F. BABINGER, Die Geschichtsschreiber..., op. cit., p. 403.

32. Ibidem, p. 403; N. SAĞLAM, "Ali Emiri...", art. cit., p. 115-123. Les deux hommes se sont notamment croisés au sein de la Commission d'examen des œuvres islamiques et nationales (Asar-i islamiye ve milliye tedkik encümeni) instituée en 1915 sous la présidence d'Ali Emiri (F. A. TANSEL, "Memleketimizin acı kaybı...", art. cit., p. 270).

33. On en lira un compte rendu détaillé dans Nuri SAĞLAM, «Ali Emiri Efendi ile Mehmet Fuad Köprülü arasındaki münakaşalar-II", İlmı̂ Araştırmalar, 11, 2001, p. 89-98.

34. Ali EMIRI, «Mudhike», Osmanl Tarih ve Edebiyat Mecmuası, 1-4, 30 juin 1918, p. 73-81, p. 79-80. 
Bref, Mehmed Fuad est un parvenu: il a fait de la carrière universitaire un pis-aller. Le ton est polémique, mais le thème traité est ancien chez les lettrés ottomans: la compétence est-elle nécessairement liée à l'expérience de l'âge? Contre les modernes qui disent vouloir imposer aux vieilles barbes une méthode scientifique pour fonder l'université nouvelle, Ali Emiri se pose en modèle de l'école classique aux yeux de laquelle la seule source du savoir est la vie passée au milieu des livres. La sienne fut placée, dès son plus jeune âge, sous le signe de l'étude:

«Il me faut dire que si Dieu m’a donné autant de connaissances en histoire, c'est grâce à des enseignants de grande valeur, et que du temps où je vins au monde, on aurait dit que la ville de Diyarbakır était en soi une bibliothèque. J'allais dans la maison des descendants de feu le mufti Derviş Efendi, parmi les notables de Diyarbakır; je voyais 3 à 4000 livres. Quand je me rendais à la résidence de feu Diyarbakırlı Said Pacha, de nouveau, je trouvais autant de livres rares. Dans d'autres maisons de notable, il en était de même. Quant à nos maisons, chez mes oncles, il y avait par exemple chez mon oncle, son excellence Şaban Kami Efendi, sans exagération, 10000 volumes de livres sublimes. J'eus accès à la totalité des livres. Et moi, nuit et jour, je n'interrompais pas la lecture de livres inconnus " ${ }^{35}$.

Ali Emiri dit vrai: il a passé sa vie à collectionner les livres. Selon une rumeur, il aurait même accepté un poste au Yémen - une destination peu recherchée parmi les employés de l'État -, dans l'espoir d'y découvrir un manuscrit des plus rares ${ }^{36}$. Mais il force le trait de l'opposition, entre le provincial qui a écumé l'Empire avant de venir diffuser son savoir dans la capitale impériale, et le fils de famille qui n'a jamais quitté Stamboul. Au moins sur un point: Mehmed Fuad a également passé ses nuits et ses jours au milieu des livres de son père, et dans le silence de la bibliothèque des Köprülü, toute proche de la maison familiale. Il a peut-être su jouer de ses relations pour entrer à l'université, mais il n'ignore pas la valeur des livres et mesure le temps qu'il faut leur consacrer. Pour le reste, l'homme a-t-il les moyens de ses ambitions? Est-il au moins honnête? Ali Emiri en doute fort. Sur un terrain où, sans doute, son adversaire ne l'attend pas, le voici qui sort sa botte secrète:

«Mais revenons à Fuad Bey. Dans mon précédent article [...], en recourant à la satire, j’avais dit que vous deviez dire: "mon père est Faiz Bey, son père est Ahmed Ziya Bey, son père est Ismail Afif Bey, son père et ainsi de suite, à la fin, son père est Köprülü Mehmed Pacha". Le malheur est que vous ne soyez même pas capable d'énoncer votre généalogie. Que moi, au moins, je le dise. Et vous, écoutez.

Votre père est Faiz Bey, votre grand-père est Ahmed Ziya Bey, son père est Ismail Afif Bey, son père est Afif Bey, son père est Numan Bey, son père est Osman Bey, son père est Mehmed Bey, son père est Kıblelizâde Ali Bey, son père est Kıbleli Mustafa Pacha, qui comptait parmi les vizirs. On voit ainsi que ni votre lignée (sülale) ni votre nom (şöhret) ne sont Köprülüzâde. C'est Kıblelizâde. Kıbleli Mustafa Pacha était le beau-frère de Köprülü Mehmed Pacha. Vous, vous avez formé un lien par la tante ${ }^{37}$ avec les Köprülüzâde. Allez-y, si vous en avez la carrure. Je vous en prie, apportez-moi la contradiction en produisant un ensemble de documents. Si vous n'êtes pas en mesure de le faire, plutôt que de continuer à vous rendre

35. Ibidem, p. 80.

36. J. DENY, "Ali Emiri Efendi», art. cit., p. 376.

37. L'auteur emploie le terme teyzezâde qui renvoie généralement à la tante maternelle, alors qu'il s'agit ici d'un rattachement paternel. 
ridicule publiquement, signez de cette manière: Kiblelizâde Mehmed Fuad. Si le maitre est froissé, que peut-on y faire? Vous n'êtes pas sans connaître le proverbe: un mauvais calcul est toujours un mauvais calcul ${ }^{38}$.

Voici Fuad Köprülü pris au piège de ses propres déclarations d'ascendance. Le procédé rhétorique ne trompe pas son contradicteur, celui qui consiste à couper la généalogie en son milieu ("et ainsi de suite»), pour aboutir à un ancêtre éponyme: bien des lignées chérifiennes ou soufies y recourent ${ }^{39}$. La leçon de généalogie se veut une leçon faite au professeur: comment croire dans le savoir de quelqu'un qui n'est même pas capable de reconstituer sa propre généalogie? Ali Emiri, en revanche, en bon spécialiste qu'il se dit être, a mené l'enquête; il a identifié le frère de l'arrière-grand-père de Mehmed Fuad, désigné sous un nom de famille différent: Kiblelizâde Mehmed Vassaf ${ }^{40}$. Que je précise ici que l'usage autorise qu'un surnom conféré intuitu personae (ce qu'on appelle un lakab) soit transformé en patronyme par l'adjonction du suffixe -zâde (littéralement "fils de»), avant de devenir, s'il est repris à la génération suivante, un nom de famille. Ali Emiri a ensuite identifié l'ancêtre éponyme de la lignée Kiblelizâde, son épitaphe et ses origines géographiques (la bourgade de Tokat). Puis, il a complété l'arbre, que je reconstitue dans le document 6 ci-après à partir de ses écrits:

La consultation de documents d'archives permet de confirmer la transmission du nom Kibleli pour les deux premières générations (Ali Bey et Mehmed Bey ${ }^{41}$ ), mais pas pour les suivantes (Osman Bey et Numan Bey). On peut supposer à bon droit que ces descendants dont nous perdons la trace n'ont pas occupé de fonctions assez importantes pour qu'on puisse les retrouver aisément. Ali Emiri a raison sur un autre point: un nom de famille en -zâde suppose deux conditions: un ancêtre éponyme doté de ce nom, et au moins un descendant direct qui le transforme en patronyme par l'adjonction de -zâde. Ensuite, le lakab est transmis comme nom patrilinéaire. Or que révèlent les compléments apportés à la généalogie? (voir document 7 , page suivante)

Ils révèlent que les Köprülü transmettaient leur nom en -zâde sur un mode patrilinéaire direct: le lakab (Köprülü) de Mehmed est porté comme patronyme par ses deux fils; puis, à la troisième génération, il devient nom de famille. Les filles de Köprülü ne transmettent en revanche aucun nom. Qu'en est-il du frère de Köprülü, Hasan A ğa ? Il est connu sous le lakab «Mevlevi», confrérie soufie dont il fut membre. Il se trouve que c'est un nom que porte aussi son fils,

38. Ibidem, p. 79.

39. Abdülbâkî GÖLPINARLI, Yunus Emre. Hayatı, Istanbul, Bozkurt basımevi, 1936, p. 328; Martin VAN BRUINESSEN, "The Qadiriyya and the Lineages of Qadiri Shaykhs in Kurdistan", in M. VAN Bruinessen, Mullas, Sufis and Heretics: The Role of Religion in Kurdish Society, Istanbul, Isis, 2000, p. 213-229, p. 216; Nathalie ClAYER, Mystiques, État et société. Les Halvetis dans l'aire balkanique de la fin du XV siècle à nos jours, Leyde, Brill, 1994, p. 59-60.

40. "Kiblelizâde Mehmed Vassaf Bey», Osmanlı Tarih ve Edebiyat Mecmuası, 2-23, 31 janvier 1920 , p. 553-559, p. 554.

41. Archives ottomanes de la Présidence du Conseil (Başbakanlık Osmanlı Arşivi), Istanbul (dorénavant BOA) (IE. ML 38/3731, daté du 10 juin 1694 [17 L 1105]; BOA, AE.SAMD.III 207/19989, daté du 26 décembre 1715 [29 Z 1127]). 


\section{DOCUMENT 6}

La généalogie de Mehmed Fuad Köprülü selon Ali Emiri

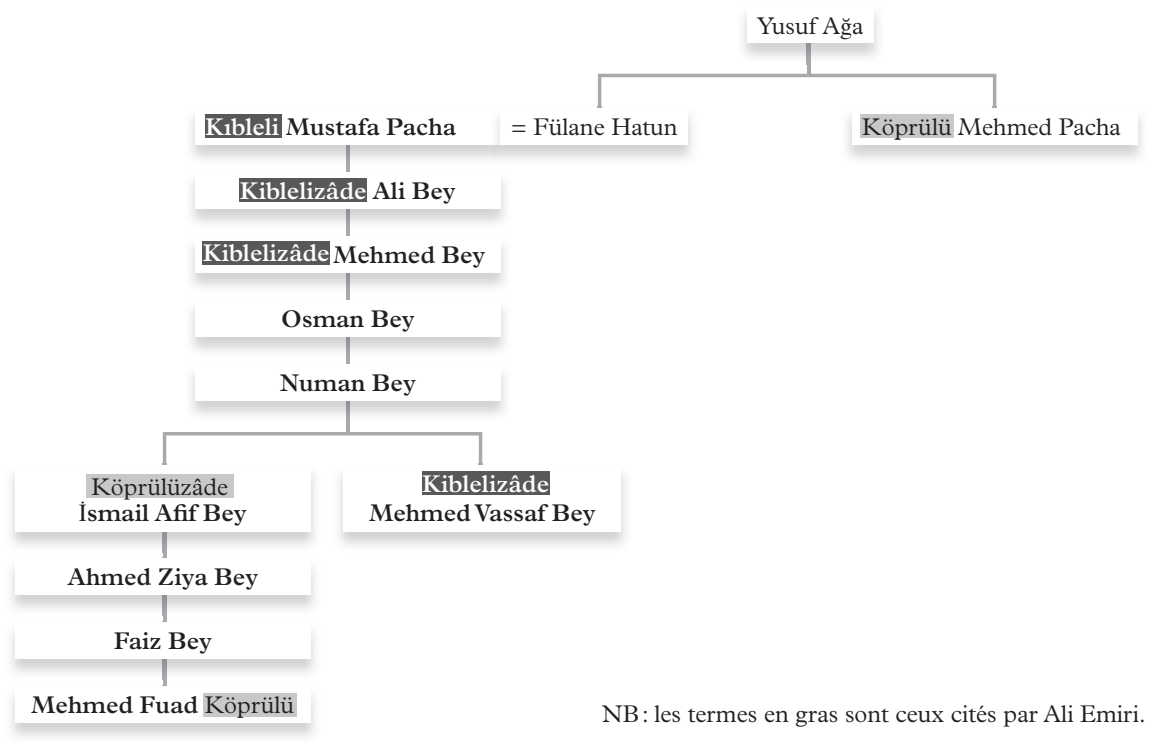

DOCUMENT 7

La généalogie de Mehmed Fuad Köprülü complétée

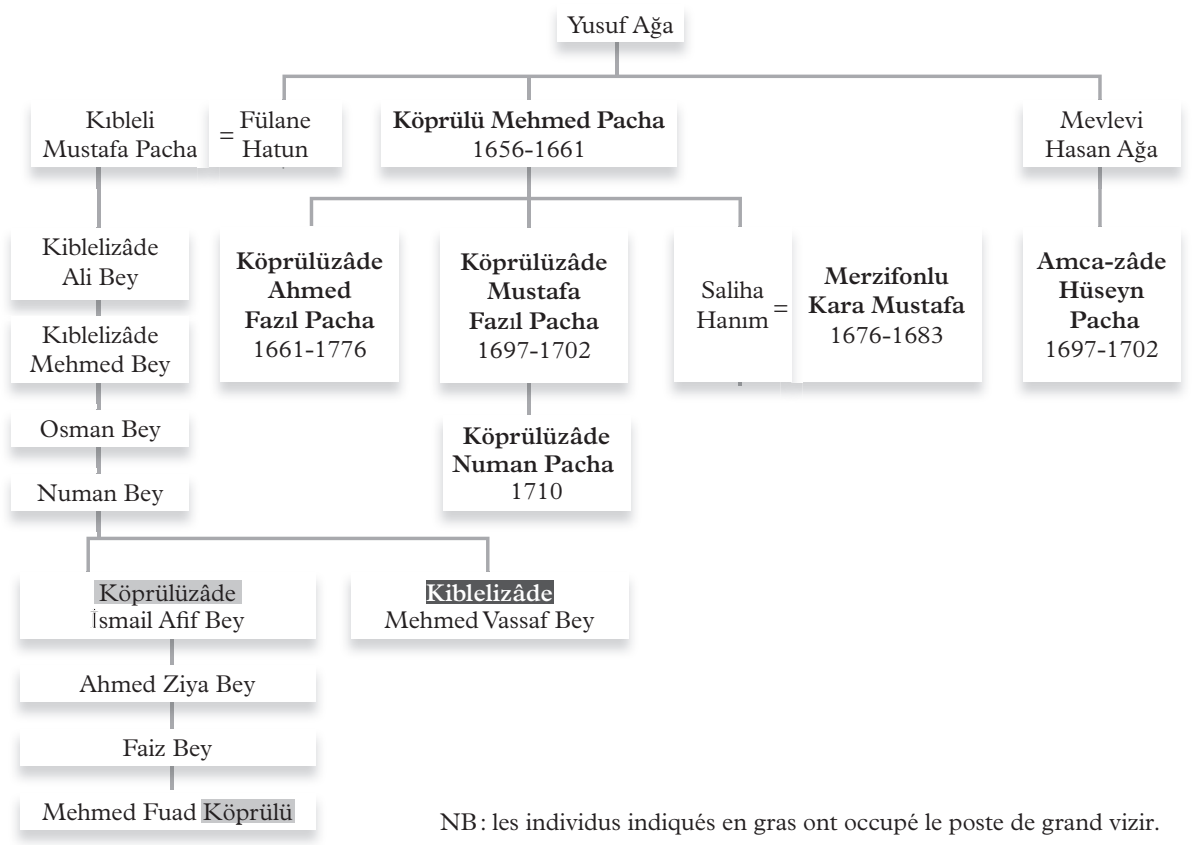


mais moins comme patronyme que comme signe d'appartenance à la même confrérie. Si Hüseyn Pacha est connu sous deux noms qui le rattachent à la famille, c'est par la branche des Köprülü: Amcazâde, autrement dit, "fils de l'oncle " ${ }^{42}$; c'est ainsi que les enfants de Mehmed Köprülü auraient appelé leur cousin Hüseyn - ce lien de parenté ne dispose pas de lexème en $\operatorname{turc}^{43}$; cette désignation est doublée de "yeğen", c'est-à-dire "neveu». L'homme porte, au creux même de son nom, les couleurs de son glorieux parent à qui il doit sa carrière. En revanche, on ne trouve trace d'aucun nom qu'il aurait transmis à ses descendants ${ }^{44}$. Bref, la reconstitution généalogique ne permet d'identifier qu'un usurpateur: Ismail Afif Bey, l'arrière-grand-père de Mehmed Fuad Köprülü. C'est vers lui qu'il faut orienter l'enquête.

\section{L'AUTRE ANCÊTRE}

La recherche d'un Köprülüzâde Ismail Afif Bey dans les documents d'archives ne donne aucun résultat. En revanche, nous savons où se trouve sa tombe: dans l'enclos des Köprülü. Cela ne fait pas de lui un usurpateur: l'hospitalité funéraire entre collatéraux était une pratique courante dans les cimetières de famille-le complexe des cousins Amcazâde situé non loin de là compte au moins sept inhumés cités sous le nom Köprülüzâde ${ }^{45}$. C'est le texte de l'épitaphe qui en établit la preuve: Ismail Afif ne figure certes pas sous le nom Köprülüzâde, mais comme étant «issus de la lignée» (sülale) de Köprülü Mehmed Pacha. Il est vrai, dans des documents de l'époque, le terme sülale renvoie à une unité familiale horizontale (grande maison, household, ou hanedan en turc) incluant également les apparentés, les clients et les serviteurs. Mais l'usage dominant renvoie à une descendance patrilinéaire. Un dictionnaire propose cette définition: "the whole line of male descents of a man, his male posterity" ${ }^{46}$. Un autre se fait encore plus concret: «ce qui est tiré, extrait, ou qui sort d'un autre corps", notamment - on ne peut être plus précis - le sperme ${ }^{47}$. Or Ismail Afif Bey n'a rien à voir avec celui de Köprülü̈8 ${ }^{48}$ Il devrait donc plutôt dire que sa

42. Şennur AYDIN, "Amcazâde Hüseyin Paşa», DYA, 3, 1991, p. 8-10.

43. Ruth C. BusCH, "Over the bounding domain. The limits of kinship and kinship terms in Turkish", Anthropological Linguistics, 1974, 16-8, p. 415-419, p. 416.

44. Il eut plusieurs filles. L'une d'entre elles aurait épousé un grand vizir, Ahmed Pacha (Sicill-i Osmanı̂, Westmead, Gregg, 1971, 2, p. 202).

45. Plusieurs membres de sa descendance y furent inhumés. Cela dit, un Köprülü Sadık Mehmed Bey s'y trouve également (Nicolas VATin, Stéphane Yerasimos, Les cimetières dans la ville. Statut, choix et organisation des lieux d'inhumation dans Istanbul intra muros, Paris, Maisonneuve et Larose, 2001, p. 125). Çobanoğlu parle de 21 tombes au total (Ahmet Vefa ÇOBANOĞLU, "Amcazade Hüseyin Paşa külliyesi”, İstanbul Ansiklopedisi, 1, Istanbul, Kültür Bakanlığı, 1993, p. 236-239, p. 239). Voir aussi Erdem YÜCEL, "Amcazade Hüseyin Paşa Külliyesi», Vakıflar Dergisi, 8, 1968, p. 249-266.

46. Sir James W. RedHouse, A Turkish and English Lexicon, Istanbul, Çağrı Yayınları, 1978, p. 1070.

47. Thomas-Xavier BIANCHI, Jean-Daniel KIEfFER, Dictionnaire turc-français, Paris, DondeyDupré, 1850, p. 1044-5.

48. Cela n'a pas échappé à N. Vatin et S. Yerasimos qui parlent de lui comme d'un "parent par alliance des Köprülüzâde" (Les cimetières..., op. cit., p. 138). 


\section{DOCUMENT 8}

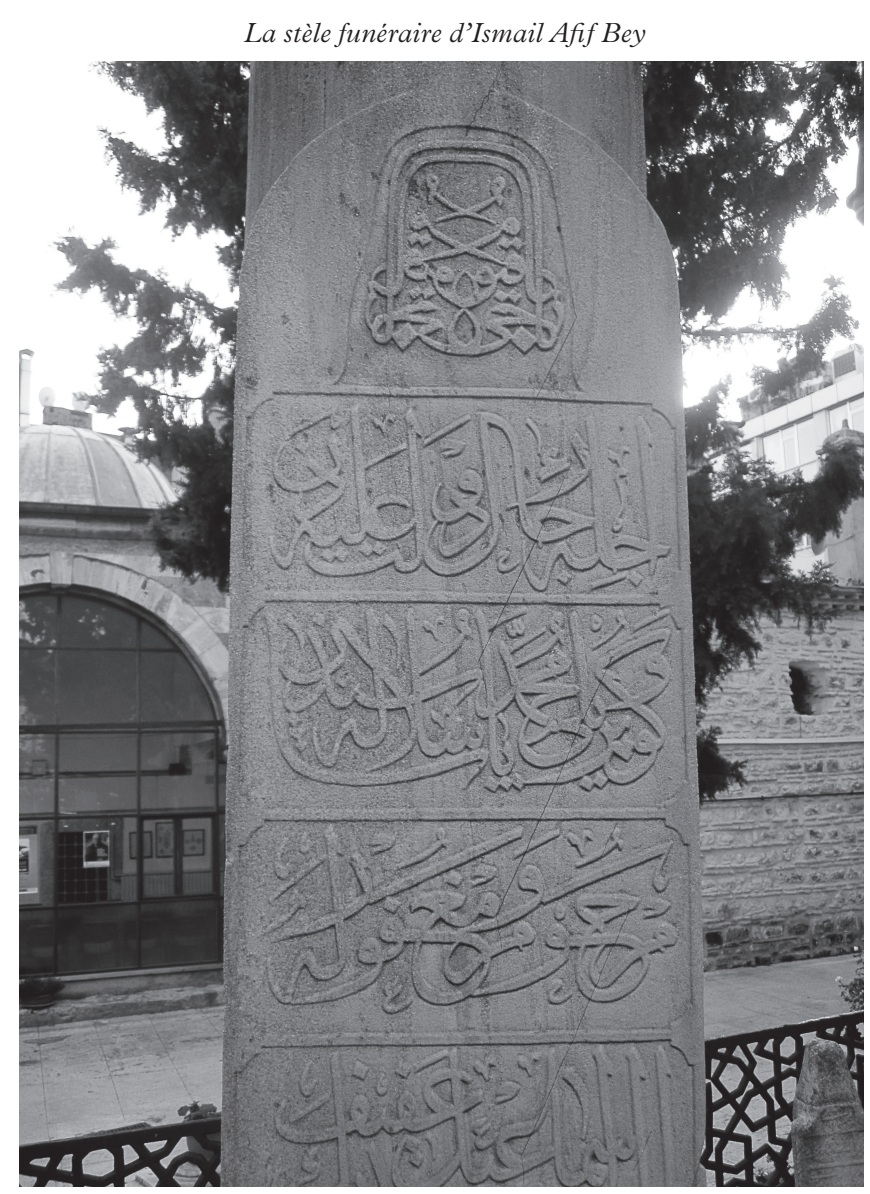

"Ecille-i rical-i devlet-i aliyeden Köprülü Mehmed Paşa sülalesinden Merhum ve măgfur ile

Es-seyyid Ismail Afif Bey

Ruhi içün el fatiha

1288"
«La fatiha pour l'âme de Es-seyyid Ismail Afif Bey, qui jouit de la miséricorde et du pardon, qui fait partie des hauts dignitaires de l'État ottoman, et qui est issu de la lignée de Köprülü Mehmed Pacha. 1288 [1872]"

lignée est apparentée (mensub) à celle des Köprülü. Cela ne règle pas la question de l'usage qu'il aurait fait, de son vivant, du nom usurpé. Au contraire, l'objet de l'usurpation s'en tient peut-être à la seule inhumation. Sur cette hypothèse qu'Ali Emiri n'envisage pas, il faut que je m'explique.

L'homme meurt en 1872. Or, depuis les années 1860, les inhumations intra muros, jusqu'alors exceptionnelles, le deviennent encore davantage: il y va de la nécessaire protection des lieux publics face aux risques d'épidémie. Dans le règlement publié le 30 mai 1869, il est désormais strictement interdit d'inhumer 
notamment dans les cimetières des mosquées ${ }^{49}$. Cela dit, des exemptions sont prévues, notamment pour les membres de la famille des fondateurs d'édifices destinés à l'exercice du culte ${ }^{50}$. C'est exactement de ce cadre que relève le complexe des Köprülü, mais pas l'inhumé. Ni le texte turc (evlad u ahfad), ni le texte français (descendants «en ligne directe») du règlement ne laissent planer d'ambiguïté. C'est peut-être pour cette seule raison (avoir une bonne place dans un cimetière intra muros) qu'Ismail Afif aurait falsifié son ascendance. Ou bien, c'est qu'il voulait (lui ou les siens) se couvrir, dans la mort, du prestige exercé par les Köprülü sur la société de son temps. L'hypothèse d'Ali Emiri ne peut être complètement écartée, d'autant qu'il vient l'étayer dans un article ultérieur:

«En vérité, les Kıblelizâde sont une lignée de noblesse estimée et connue dans les annales; c'est une famille honorée continûment depuis plus de trois siècles. Cependant, dans les derniers temps, quelques dégénérés (nahalef) ont été produits; ils ont renié leurs ancêtres et leur famille; ils ont changé leur signature en "Köprülüzâde". On dirait qu'ils ont trompé tout le monde. Ils ont falsifié l'histoire. L'effacement du nom et de la renommée de la lignée Kiblelizâde a rendu vaines les explications historiques "51.

Ali Emiri exagère l'ancienneté de la lignée des Kıbleli : en vérité, au-delà de l'ancêtre éponyme Mustafa, la reconstitution n'irait pas bien loin. Il use d'un procédé rhétorique qui lui permet de rendre encore plus aberrant le reniement dont il accuse les ancêtres directs de Mehmed Fuad. Mais il a raison pour ce qui est de la différence de prestige : les Kibleli n'ont certes pas démérité comme famille d'État, mais ils n'ont jamais atteint la splendeur de leurs cousins: un vizir, en tout et pour tout, ce n'est pas grand-chose face aux six grands vizirs alignés par les Köprülü. Certes, au XIX ${ }^{\mathrm{e}}$ siècle, les deux lignées ne sont plus que l'ombre d'elles-mêmes. À ceci près que les Köprülü restent une référence incomparablement plus célèbre. Sans doute les descendants falsificateurs veulent-ils se l'attacher, alors que progresse une "culture du génie familial» dans l'administration publique où ils restent actifs ${ }^{52}$.

\section{De L'USURPation Chez les Ottomans}

Supposons à présent que les descendants des Köprülü en ligne directe aient été informés de la présence d'Ismail Afif parmi les inhumés. Il est difficile de déterminer ce qu'ils auraient pu en penser. Il n'aurait servi à rien en tout

49. ARISTARCHI BEY, Législation ottomane ou recueil des lois, règlements, ordonnances, traités, capitulations et autres documents officiels de l'Empire ottoman, 3, Constantinople, 1874, p. 157-158; Osman NURI ERGIN, Mecelle-i umur-i belediyye, 4, Istanbul, İstanbul Büyükşehir Belediyesi Yayınları, 1995 (2 éd.), p. 2141-2142.

50. Nicolas VATIN, "L'inhumation intra muros à Istanbul à l'époque ottomane», in Gilles VEINSTEIN (éd.), Les Ottomans et la mort. Permanances et mutations, Leyde, Brill, 1996, p. 157-174; N. VATIN, S. Yerasimos, Les cimetières..., op. cit., p. 23-24.

51. Ali EMIRI, «Kiblelizade Mehmed...», art. cit., p. 554.

52. O. BOUQUET, Les pachas du sultan. Essai sur les agents supérieurs de l'État ottoman (1839-1909), Louvain, Peeters, 2007, p. 205, 208, 215-216. 
cas de s'en plaindre auprès des autorités: dans le droit ottoman de la dernière période, l'usurpation du nom n'est pas passible de poursuite. Dans ce même numéro, Marc Aymes cite un procès-verbal du Conseil d'État de 1906 dans lequel il est spécifié que «s'attribuer à titre temporaire le nom d'un autre» est considéré comme n'émanant pas «de personnes essentiellement mal intentionnées: il s'agit plutôt, lorsque cela se produit, d'individus simplement soucieux de s'épargner la fatigue de faire émettre un certificat, et voulant éviter, faute de ressources, d'avoir à s'acquitter des droits afférents „ ${ }^{53}$. Ce procès-verbal correspond parfaitement à ce que l'on sait de l'usage du nom ottoman.

Les sujets du sultan vivaient dans un monde de relative liberté onomastique. Le nom était souvent conféré au hasard de l'existence, selon telle ou telle situation, tantôt conservé, tantôt remplacé par un autre. Il n'était pas défendu comme référent honorifique. Loin d'être exclusif ou inaliénable, il ne relevait d'aucun acte notarié. C'était un opérateur parmi d'autres de l'identification des sujets et de l'institution de police. Aux yeux des autorités, cette inconstance des noms ne menaçait pas l'ordre public, à l'inverse d'autres usages de la dénomination considérés, à des degrés divers, comme des actes séditieux. $\mathrm{Au}$ moins trois d'entre eux étaient des lieux de catégorisation juridique et d'action en justice: l'imposture, la falsification et l'usurpation de titre. La première (en turc, düzme, düzmece) pouvait être passible des tribunaux en ce qu'elle introduisait une confusion dans la juste distribution des privilèges et des droits ${ }^{54}$. La deuxième était répréhensible dès lors qu'elle portait atteinte à un document officiel, considéré comme propriété de l'État, déclaré comme absolument inaltérable une fois la copie du scribe achevée ${ }^{55}$. La troisième marquait l'appropriation individuelle arbitraire d'un bien transmis en propre par une autorité qui en revendiquait le monopole. Il en allait ainsi des titres d'État, tel pacha, qui ne pouvait être conféré que sur ordre du sultan. Il en allait ainsi de la condition de descendant du Prophète (seyyid ou şerif) qui ne pouvait être validée que par le syndic appelé nakibüleşraf $f^{56}$.

53. Marc Aymes, "Prêts-noms. Politique du métonyme» (dans ce même numéro; traduction de l'auteur).

54. Bernard HAYKEL, "Dissembling descent, or how the barber lost his turban in eighteenth-century Zaydî Yemen", Islamic Law and Society, 9-2, 2002, p. 194-225; Ișık TAMDOĞAN, "La fille du meunier et l'épouse du gouverneur d'Adana. L'histoire d'un cas d'imposture au début du XVIII siècle", Revue des mondes musulmans et de la Méditerranée, 127, 2010, p. 143-155.

55. Sur l'interdit qui pèse sur les ratures et biffages des documents administratifs, voir notamment M. AYMES, "La lettre saisit l'esprit. Histoire probatoire d'un programme de réforme", Cahiers du centre de recherches historiques, 45, avril 2010, p. 75-93; ID., "Le territoire de l'évitement», in Christine JUNGEN, Jihane SFEIR (éd.), Archiver au Moyen-Orient, Paris, Karthala (à paraître).

56. Sur les titres d'État, je renvoie à O. BouQueT, Les pachas..., op. cit., p. 187-189; sur les titres chérifiens, à Ruya KILIÇ, "Sayyids and sharīfs in the Ottoman state: on the borders of the true and the false", Muslim World: a Fournal devoted to the study of Islam and Christian-Muslim Relations, 96-1, janvier 2006, p. 21-35; Hülya CANBAKAL, "The Ottoman state and descendants of the Prophet in Anatolia and the Balkans (c. 1500-1700)", Fournal of Economic and Social History of the Orient, 52-3, 2009, p. 542-578. 
Au moins dès la fin du XVI ${ }^{\mathrm{e}}$ siècle, l'invention d'origines mahométanes devint une pratique courante: 60 des 237 grands muftis se disaient alors seyyid ${ }^{57}$; à Alep au XVIII siècle, $58 \%$ des familles de notables étaient répertoriées sous ce statut $^{58}$. Il y avait beaucoup à y gagner, entre autres la reconnaissance d'une distinction héréditaire dans la société environnante, doublée de précieuses possibilités d'exemption fiscale et militaire. Tel influent doté d'une bourse solide ne rencontrait guère d'obstacle infranchissable pour acheter le titre ${ }^{59}$. Dans des provinces où ils étaient inconnus, des individus se pavanaient avec le turban vert, privilège des chérifiens, dans l'espoir de faire enregistrer leurs enfants sous ce statut ${ }^{60}$. Les syndics des descendants disposaient de tables généalogiques et de listes d'allocations versées aux descendants, afin de faire la chasse aux acheteurs de titre, souvent en vain, il est vrai ${ }^{61}$ : si des familles perdaient leur privilège pour production de documents faux, d'autres maintenaient leur titre sur la base de l'ouï-dire (tawatur) ${ }^{62}$. Ils étaient bien rares ceux qui disaient ne pas vouloir s'en prévaloir, à l'instar de ce notable tunisois du XIX ${ }^{\mathrm{e}}$ siècle, Ibrâhîm al-Riyâhî; alors qu'il demandait à son père la raison pour laquelle la famille ne mettait pas en avant son ascendance chérifienne "comme tant d'autres, aujourd'hui», celui-ci lui fit cette réponse: «nous n'avons pas besoin de cela car Fâtima saura, au jour du Jugement, reconnaître ses enfants " ${ }^{63}$.

Ces titres relevaient du droit car ils étaient sinon catégories d'État, du moins inscrits dans les registres de l'administration. Les noms de famille ne l'étaient pas: le sultan ne reconnaissait aucune seigneurie, aucune noblesse de terre ou d'État. Tout juste tolérait-il l'existence de lignées pré-ottomanes. On ne saurait comprendre le mode de fonctionnement du nom ottoman si l'on ne souligne pas cette particularité. Bien sûr, on dira que dans d'autres pays, le nom de famille n'était pas davantage un objet de prescription juridique: la jurisprudence française, par exemple, avait été amenée à considérer comme "propriétés familiales» non pas le nom, mais le titre et le blason ${ }^{64}$; pour des raisons principalement fiscales, l'usage voulait que l'usurpation des titres fût tolérée pour les nobles, mais réprimée pour les non-nobles ${ }^{65}$. Non seulement la défense du nom de famille s'imposa tardivement - sous la III ${ }^{\mathrm{e}}$ République en fait -, mais elle ne fit jamais consensus parmi les juristes. Si le juge était régulièrement sollicité par les familles, il était souvent bien en peine de trancher: le

57. Madeleine ZILFI, "Elite circulation in the Ottoman Empire: great mollas of the eighteenth century", Fournal of Economic and Social History of the Orient, 26, 1983, p. 318-363, p. 353.

58. Hülya CANBAKAL, "On the "nobility" of provincial notables", in Antonis ANASTASOPOULOS (ed.), Provincial Elites in the Ottoman Empire, Rethymnon, Crete University Press, 2005, p. 39-50, p. 39.

59. R. KiLIÇ, «Sayyids... ", art. cit., p. 30.

60. Ibidem, p. 29.

61. H. CANBAKAL, "On "the nobility"...", art. cit, p. 42; R. KILIÇ, «Sayyids...", art. cit., p. 30.

62. Ibidem, p. 28.

63. Mohammed El-Aziz BEN ACHOUR, «Les Šarifs à Tunis au temps des Deys et des Beys (XVII ${ }_{-}$ $\mathrm{XIX}^{\mathrm{e}}$ siècle), Oriente Moderno, 18-2, 1999, p. 341-350, p. 345.

64. T. BARTHÉLEMY, "Noms patronymiques...», art. cit., p. 65.

65. Ibidem, p. 75. 
législateur tardait en effet à reconnaître des catégories liées à une classification hiérarchique abolie ${ }^{66}$. Mais les Ottomans étaient dans une autre situation: aucun sujet du sultan n'eût jamais songé à saisir une quelconque autorité pour défendre son nom. Et selon toute probabilité, aucun descendant n'eût encore moins estimé utile de consulter aucun érudit ou spécialiste dans le but de rassembler des preuves de descendance contre un usurpateur.

\section{MehMEd FuAd PERSISTE et SIGNe (KöPRÜLÜ)}

Quel que soit le fondement juridique ou moral de l'accusation auquel Ali Emiri se réfère, "le maître» est démasqué. Qu'a-t-il pourtant à se reprocher? L'historien Ö. F. Akün a raison de dire que Mehmed Fuad Köprülü n'est pas l'auteur de l'usurpation, du "problème lié aux Köprülüzâde» ("Köprülüzâdelik meselesi») ${ }^{67}$. Ce nom, ce sont ses ancêtres qui le lui ont transmis. Il n'était qu'un jeune homme quand le fils d'Ismail Afif, son grand-père, le diplomate Ahmed Ziya, se fit mentionner - et cette fois-ci dans un contexte officiel (un annuaire du ministère des Affaires étrangères) - comme «étant issu de la lignée de l'ancien grand vizir Köprülü Mehmed Pacha "68. On comprend que Mehmed Fuad n'estime pas avoir à se défendre sur ce point particulier. Mais il semble assez "froissé» pour répondre à Ali Emiri, d'un mot, en quelques lignes, et seulement sur le terrain de ses œuvres:

Lumières hamidiennes $^{69}$, pauvre poète! Il peut bien continuer autant qu'il le souhaite les invectives indécentes et ridicules; il nous inspire une profonde pitié.

Le lettré est une personne qui se mesure à son capital de modestie.

Nous lisons cet hémistiche. Nous haussons les épaules, en signe d'indifférence. Et nous passons ${ }^{70}$.

C'est déjà un mot de trop, selon un observateur allemand qui rendit compte de l'altercation. C'est un mot élégant, il est vrai: face aux "invectives", l'éthique du «lettré», comme de l'«homme d'éducation" (edib, le terme employé, a bien ce double sens), commande la plus "profonde pitié». Mehmed Fuad s'en tient à quelques commentaires sur les erreurs qui lui sont imputées. Et puis, il conclut, d'une phrase de sagesse, à l'adresse d'Ali Emiri dont il ne prend pas la peine de citer le nom. Enfin il signe, sous ce nom qu'on voudrait lui retirer:

66. Ibidem, p. 77.

67. Ö. F. AKÜN, «Mehmed Fuad Köprülü», art. cit., p. 472.

68. «Bükreş sefiri saadetlü Ahmed Ziya Beyefendi hazretleri sadaret-i uzma müsteşarı esbak müteveffa İsmail Bey’in mahdumu olup sadr-1 esbak Köprülü Mehmed Paşa sülalesindendir» (Devlet- $i$ aliye-i osmaniye hariciye nezaret-i celilesi'nin salnamesi, Istanbul, 1306, p. 549).

69. En turc, Levami ül-hamidiyye est le titre d'un ouvrage publié par Ali Emiri (Istanbul, Alem Matbaas1, 1312/1894), dans lequel il chante la gloire de la dynastie au pouvoir et du sultan régnant.

70. "Levami' al-hamidiye» şair-i rekiki, galiz ve gülünç şetmlerine istediği kadar devam edebilir; biz de ona karşı, derin bir terahümle:

Edib olur kişi sermaye-i hayası kadar

Mısra'ını okur, omuzlarımızı silker geçeriz. 
Köprülüzâde Mehmed Fuad. Il n'est pas le seul, ensuite, à persister : il figure sous ce même nom dans des documents d'État, les répertoires biographiques, ses propres publications, la revue qu'il dirige, en un mot, partout où il est cité, en Turquie comme à l'étranger ${ }^{71}$. Quelques rares auteurs ne se privent pas d'y faire allusion ${ }^{72}$. Mais l'affaire ne connaît plus d'épisode retentissant. Seul Ali Emiri s'obstine: dans ses écrits ultérieurs, pour lui l'usurpateur reste "Kiblelizâde Fuad", comme il le cite ${ }^{73}$. Vieil homme amer, il disparaît en janvier 1924. Deux mois trop tôt pour voir son ennemi réaliser l'ambition qu'il disait avoir percée à jour chez lui, ou presque : à défaut d'être ministre de l'Instruction, Mehmed Fuad est au moins son Secrétaire général (müsteşar) ${ }^{74}$.

1934. La loi des noms impose à chaque citoyen turc l'obligation du nom de famille. Mehmed Fuad opte pour Köprülü, amputé du suffixe -zâde dans lequel le législateur républicain lit une marque d'ancien régime, proscrite parmi d'autres titres et désignations ${ }^{75}$. Qu'à cela ne tienne: sa mère en fait autant, d'autres descendants également qui sont tout autant des Kıbleli, par exemple son cousin, le spécialiste de littérature allemande, Cemal Köprülü $(1893-1979)^{76}$. Il faut préciser ici que la loi interdit le choix d'un nom qui aurait été porté par d'autres ancêtres que les siens ${ }^{77}$. Or des enquêtes ont révélé que des noms célèbres avaient été alors adoptés par des branches différentes; comme les autorités s'efforçaient de veiller à réduire les situations d'homonymie, des familles "héritières" se retrouvèrent privées du prestige convoité $^{78}$. De son côté, Mehmed Fuad est en pleine conformité avec la loi: le nom de son arrière-grand-père fait foi. Son choix ne surprend personne,

71. Ainsi lors de ses nominations comme Secrétaire général du ministère de l'Instruction (27 mars 1924), Doyen de la Faculté de lettres (4 juin 1925), Président de la même faculté (28 mai 1928) (Cumhuriyet Arşivi Kataloglarl, http://www.devletarsivleri.gov.tr/katalog/; consulté le 15 décembre 2011). Voir également Mehmet ZEKİ, Mahmoud PATCHADJI, Encyclopédie biographique de Turquie, Istanbul, Babok \& Fils, 1928, p. 96. Il signe Köprülüzâde Mehmed Fuad, notamment dans deux de ses livres: Bugunkü Edebiyat, Istanbul, Cihan Biraderler matbaası, 1924; Türk Edebiyatı Tarihi, Istanbul, Devlet Matbaas1, 1928. Dans la bibliographie parue en 1931, trois titres d'ouvrage figurent sous le nom «Pr. Dr. Köprülüzade Mehmed Fuad», un seul sous le nom «Pr. Dr Mehmet Fuat» (Biblioyoğrafya I. 1928-1931, Istanbul, Devlet Matbaas1, 1931, p. 11). L. Bouvat le cite sous le nom de "Kieuprulizadè Mehmed Fuâd" ("Les premiers mystiques...", art. cit.), et F. BABINGER de "Köprülüzâde Mehmed Fu'âd Bej" (Die Geschichtsschreiber..., op.cit., p. 403).

72. Rıza Nur, par exemple, dans une publication datée de 1935 (cité in Seher Erdoğan ÇELTIK, "Ali Emirî'nin Osmanlı Tarih ve Edebiyat Mecmuası Üzerine Bir İnceleme», thèse de licence supérieure, Ankara, Gazi Üniversitesi, 2007, p. 110).

73. Ali EMİRI, «Hadim ve hafız-1 emanet-i mübareke, hulefa-yı celile-i osmaniye'nin şeref-silsile-i siyadetleri ve ilm-i celil-i ensabın fevaidi", Osmanl Tarih ve Edebiyat Mecmuası, 2-19, 30 septembre 1919, p. 418.

74. Cumhuriyet Arşivi Kataloglar, http://www.devletarsivleri.gov.tr/katalog/; consulté le 15 décembre 2011.

75. Pour des reproductions de lettres personnelles signées sous le nom Köprülü, voir Zeynep Süslü (ed.), Fuad Köprülü'den Fevziye Abdullah Tansel'e Mektuplar, Istanbul, Istanbul Büyükşehir Belediyesi, 2006.

76. Fevziye TANSEL, "Ahmed Cemal Köprülü (19 Mayıs 1893-1 Şubat 1979)», Belleten, XLIII172,1979 , p. $841-854$.

77. Article $13 \mathrm{du}$ "soy adı nizamnamesi» [décret d'application du nom de famille], Yeni Kanunlar, 199 , p. $1-16$, p. 4.

78. Paul J. Magnarella, Tradition and Change in a Turkish Town, New York, John Wiley and sons, 1974, p. 86 
et s'impose aussitôt ${ }^{79}$. Sa célébrité est telle que, quand en 1935 un journaliste offre au grand public de passer «une heure avec Köprülü ${ }^{80}$, il est inutile de préciser de qui il s'agit. L'illustre professeur continue d'être ce qu'il est depuis les débuts de la République: le premier des Köprülü.

\section{LES CONFUSIONS DU NOM}

Un Köprülü, issu des Köprülü : c'est ainsi que les contemporains, à commencer par les historiens, voient Mehmed Fuad ${ }^{81}$. Le lien de parenté est suggéré quand il n'est pas explicite: dans le volume d'hommage dédié à la mémoire de Mehmed Fuad Köprülü, Yusuf Blaşkoviç choisit, ni plus ni moins, de consacrer une étude au grand vizir Köprülü Mehmed Pacha ${ }^{82}$. Rares sont ceux qui désignent le professeur comme "apparenté (mensup) aux Köprülü ${ }^{83}$. Il faut attendre 1979 pour lire F. İz rétablir avec exactitude le statut de descendant de Mehmed Fuad: "Il était le fils d'un fonctionnaire, Ismâ'îl Fâ'iz Bey, qui descendait de la sœur du célèbre grand-vizir ottoman, Köprülü-Mehmed Pasha, laquelle avait épousé Kıbleli Mustafâ Pasha» ${ }^{84}$. Mais comment collègues, disciples et amis auraient-ils osé ternir la "main blanche» du maître, et porter atteinte à la réputation du corps académique? Cette explication tient, mais ne suffit pas: car une fois les contemporains disparus, l'inclusion Kibleli/Amcazâde/Köprülü a continué de prévaloir chez des spécialistes issus d'horizons différents ${ }^{85}$. Ainsi, quand l'architecte et historien Sedat Eldem étudie le célèbre yalı de Hüseyn Pacha, il le cite autant comme yalı Amcazâde que comme yalı de «Köprülü (Amcazâde) Hüseyn Pacha", comme si un nom valait pour l'autre ${ }^{86}$. Autre chose est ici en jeu qui tient à la conception même de la famille en Turquie: c'est parce

79. Dans la revue qu'il dirige (Türkiyat Mecmuası), Köprülüzâde Mehmed Fuad devient Mehmed Fuad Köprülü, à partir du volume 4, daté de 1934.

80. Hikmet Feridun Es, "Köprülü ile bir saat», Akşam, 27 Nisan 1935 (cité par Ö. F. AKÜN, "Mehmed Fuad...", art. cit., p. 486).

81. "Köprülüler soyundan» (İbrahim Alâettin GöVsA, Türk Meşhurları Ansiklopedisi, Istanbul, 1946, p. 223; Ahmet CAFeroĞLU, "Hakikî Köprülü», Türkiyat Mecmuas1, XV, 1968, p. 1-10, p. 2); «Ünlü Osmanlı vezir ailesi Köprülülerden» (Abdullah UÇMAN, «Köprülü, Mehmed Fuad», Yaşamları ve Yapıtlarıla Osmanlılar Ansiklopedisi, 2, Istanbul, YKY, 1999, p. 36-37, p. 36); "Köprülülerin hayatta bulunan en mühim uzvu (Tayyib GöKBILGIN, "Köprülüler», İslam Ansiklopedisi, 6, 1955, p. 892-908, p. 907).

82. Yusuf BLAŞKOVIÇ, "Köprülü Mehmed Paşa’nın macarca bir ahdnâmesi», Türkiyat Mecmuası, 15, 1968, p. 37-43.

83. İsmail Hikmet ERTAYLAN, Türk Edebiyatı Tarihi I-IV, Ankara, TTK, 2011, p. 897-903, p. 897.

84. Fahir İz, "Köprülü», Encyclopédie de l'islam, 2e édition, 5, 1979, p. 261-262, p. 261. Voir aussi Necdet SAKAOĞLU, «Köprülüler», Dünden Bugüne İstanbul Ansiklopedisi, 5, Istanbul, Kültür Bakanlı̆̆ı, 1993-1994, p. 91-95, p. 91; Y1lmaz ÖZTunA, Devletler ve Hânedanlar. Türkiye (1074-1990), Ankara, 1996 (3e éd.), p. 730; G. LeISER, R. DANKOFF, Early Mystics..., op. cit., p. XXVIII.

85. Ö. F. AKÜN, "Mehmed Fuad Köprülü», art. cit., p. 479.

86. Sedad H. EldeM, Köşkler ve Kasırlar, 2, Istanbul, Devlet ve Güzel Sanatlar Akademisi, 1974, p. 151, p. 179. Cela dit, il n'est pas le premier. Voir par exemple René MESGUICH, Henri SALADIN, Le yalı des Keupruli à Anatoli-Hissar, côte asiatique du Bosphore, Paris, Société des amis de Stamboul, 1915. 
qu'ils présupposent que les membres les plus illustres (y compris les gendres ou beaux-frères du fondateur éponyme) faisaient partie d'une même maison, et que les collatéraux eux-mêmes se comptaient parmi les Köprülüzâde, que les spécialistes considèrent également leurs descendants comme tels ${ }^{87}$. Or ce raisonnement ne vaut que pour une partie de l'histoire de la lignée.

À leurs yeux, les six grands vizirs (les trois de la lignée patrilinéaire, comme les autres) sont pareillement de la famille Köprülü ${ }^{88}$. D'une certaine manière, ce n'est pas inexact. La proximité du degré de parenté favorise solidarités patrimoniales et politiques. Il est juste d'employer, pour cette période, le nom Köprülü comme nom générique de plusieurs branches fédérées, qui forment au temps de leur puissance une même famille politique: c'est bien au moment où l'un d'entre eux exerce, pour la dernière fois, la fonction de grand vizir que le nom de famille se constitue (à la troisième génération). Mais ensuite, cette communauté se disloque. Chaque branche a sa propre évolution, ses propres fondations pieuses, ses propres enclos funéraires, ses propres implantations régionales, et fait famille à son tour ${ }^{89}$. Les Köprülüzâde procèdent alors à l'écriture de leur histoire. C'est dans les années 1730 que l'arrière petit-fils de Mehmet Köprülü, Ahmet Pacha, commande une chronique à la gloire des siens. Or si celle-ci est consacrée aux vizirs de la famille, seuls les dignitaires en ligne directe sont pris en compte: ni le beau-frère de Köprülü Mehmed (Kibleli Mustafa), ni son gendre (Merzifonlu Kara Mustafa) ne sont intégrés à l'hagiographie de la lignée ${ }^{90}$. Certes, les liens sont entretenus (alliances matrimoniales pour les vivants, inhumations dans les enclos de famille pour les morts). Certes, les Kibleli sont encore engagés dans l'administration des fondations pieuses des Köprülü̈1 ${ }^{91}$ Certes, les collatéraux se considèrent sans doute comme apparentés. Mais, à la différence de leurs ascendants réunis autour de la gloire de la Sublime Porte, ils ne se comptent certainement pas comme faisant partie d'une même famille. C'est dans cette évolution (non prise en compte par l'historiographie) du nom de famille, de fédérateur de household au XVII e siècle en "classificateur de lignée» au XIX ${ }^{\mathrm{e}}$ siècle, que s'inscrit la critique d'Ali Emiri ${ }^{92}$.

87. Il est pourtant inexact de dire, à l'instar de Y. ÖzTUNA (Devletler.., op. cit., p. 729), que les descendants de Kıbleli Mustafa Pacha sont "par la mère" ("ana tarafından") des Köprülü-zâde, la mère en question n'ayant jamais été elle-même une Köprülü.

88. N. SAKAOĞLU, «Köprülüler», art. cit., p. 94.

89. Comme exemple de fondation pieuse instituée par un membre de la lignée de la troisième génération, Abdullah Pacha, petit-fils de Köprülü Mehmed Pacha, voir Sultan Murat ToPÇU, «Köprülüzade Abdullah Paşa'nın 15 Cemadiel-evvel 1133-M.14 mart 1721 tarihli vakfiyesi'ne göre imar faaliyetleri ve bani kişiliği», Uluslararası Sosyal Araştırmaları Dergisi, 4-17, 2011, p. 405-415.

90. C’est ainsi que le gendre de Mehmed Köprülü Pacha, Merzifonlu Kara Mustafa, pourtant grand vizir également, n’est pas intégré à la chronique (M. F. GÖKÇEK, "Behcetî Seyyid... ", op. cit.., p. 2-3).

91. Un Kibleli du nom de Mehmed Bey est impliqué dans l'administration des vakıf de Köprülü (BOA, MAD.d 5105).

92. Claude LÉvi-STrauss, La pensée sauvage, Paris, Plon, 1962, p. 115. 


\section{UNE GUÉRILLA MONDAINE ${ }^{93}$}

Au début du siècle, le dossier du conflit Fuad Köprülü/Ali Emiri est rouvert à l'occasion de la parution de plusieurs travaux universitaires ${ }^{94}$. C'est l'effet de la place qu'occupent les deux hommes dans l'histoire des lettres ottomanes. Cette fois-ci, le sujet est abordé à froid, et la polémique sur le nom est présentée comme un aspect secondaire de la vie ou de l'œuvre des deux adversaires, au miroir d'une lutte symbolique pour la gloire des lettres et l'occupation du champ académique. C'est plutôt dans l'univers feutré des grandes familles que la question refait sensiblement surface. Les noms de pacha sont de retour.

À la suite de la loi de 1934, plusieurs lignées s'étaient vues interdites de nom de famille. Les grandes familles se voulaient discrètes. L'idéologie républicaine s'imposait. Mais une noblesse s'est peu à peu construite dans la Turquie de la fin du $\mathrm{XX}^{\mathrm{e}}$ siècle. Elle profite du contexte actuel de mise en avant du passé ottoman par le régime. Les grandes familles sont engagées dans une recherche des racines. Elles organisent des réunions, des cousinades comme on dit chez nous. Au sein de la généalogie, les noms de famille se sont multipliés, les descendants s'y perdent un peu. Le nom de l'ancêtre (ata) sert d'amer, surtout quand sa figure a été croquée au fusain ou captée par la photographie, comme ce fut le cas de plusieurs hauts dignitaires; il se fait porteur d'un "pouvoir métaphorique», d'une «propension à libérer l'imaginaire ${ }^{95}$. Plusieurs Köprülü sont gagnés par cette nouvelle mode.

Une partie d'entre eux ont toujours préservé une identification autour d'un ancrage géographique à Izmir, et sans doute autour de la fondation pieuse qui était liée au souvenir du grand vizir. Ils se réclament encore de son ascendance, y compris sur un mode matrilinéaire ${ }^{96}$. Source d'ennoblissement ${ }^{97}$ et cristallisateur progressif de l'estime sociale, le nom vaut désormais blason. Ce n'est pas rien d'être un descendant des grands vizirs Köprülü. C'est même devenu un titre de distinction, y compris pour des hauts représentants du régime. Le porte aujourd'hui un ambassadeur en fonction en qui le public voit une sorte de prince. Dans ses mémoires, une ancienne journaliste, Tuna Koprülü, mesure désormais toute la distinction que lui vaut son nom de famille ${ }^{98}$. La défense des origines semble avoir pris des allures de "guérilla mondaine». Une branche

93. Cette expression renvoie aux familles qui se disputent un nom, alors même que leurs réseaux s'entrecroisent de plus en plus (T. BARTHÉLEMY, "Noms patronymiques...», art. cit., p. 76).

94. N. SAĞLAM, "Ali Emiri Efendi ile Mehmet Fuad Köprülü arasındaki münakaşalar-I», art. cit.; N. SAĞLAM, "Ali Emiri Efendi ile Mehmet Fuad Köprülü arasındaki münakaşalar-II», art.cit.; M. F. GÖKÇEK, "Behcetî Seyyid İbrahim Efendi...», op. cit.

95. T. BARTHÉLEMY, "Noms patronymiques...», op. cit., p. 78.

96. Voir le cas de l'homme de lettres Samet AĞAOĞLU (A. Asılsoy, "Türk modernleşmesi...», art. cit., p. 26).

97. Je reprends la distinction proposée par Samuel GIBIAT (Hiérarchies sociales et ennoblissement. Les commissaires des guerres de la Maison du roi au XVIII ${ }^{e}$ siècle, Paris, École des Chartes, 2006) entre l'opération juridique d'anoblissement qui confère un statut nobiliaire, et l'ennoblissement, qui est l'acquisition lente et progressive de l'estime sociale reconnue à la noblesse.

98. Tuna KöPRÜLÜ, Beyaz Saray Anılarl, Istanbul, Remzi Kitabevi, 2003, p. 24-25. 
smyrniote conteste en effet l'authenticité historique des Köprülü d'Istanbul. Mais ceux-là disposent de leviers d'action universitaires et éditoriaux qui leur ont permis de prendre soin de leur généalogie ${ }^{99}$. Ainsi le propre fils de Mehmed Fuad Köprülü a hérité autant du prénom de son père (Fuad) que de sa profession. En tant qu'exécuteur testamentaire, il a veillé à la réactualisation bibliographique de l'œuvre; il a annoté et publié plusieurs articles posthumes ${ }^{100}$. Mais il a également occupé le champ historiographique de la mémoire familiale: il a notamment signé dans l'encyclopédie cofondée par Mehmed Fuad Köprülü un article sur le précité Amcazâde Hüseyn Pacha ${ }^{101}$. Assurément, Mehmed Fuad Köprülü était un pionnier du retour des Ottomans. Son nom a de beaux jours devant lui.

Rien n'obligeait Mehmed Fuad à changer de nom : il ne l'avait pas usurpé, il en avait hérité. Ali Emiri n'aurait-il pas manqué de se noyer dans un verre d'eau? Cette affaire personnelle était-elle une affaire d'importance ? Était-elle autre chose que le solde de tout compte d'une relation d'inimitié entre deux hommes, le produit de l'esprit d'un érudit qui aurait trop abusé des vieux manuscrits? Tout ce qui est excessif est insignifiant: il aurait peut-être mieux valu faire comme Mehmed Fuad Köprülü, passer son chemin.

Il me semble pourtant que la défense du nom des Köprülü mérite qu'on s’y intéresse: elle était le reflet de plusieurs conceptions auxquelles bien des lettrés ottomans étaient attachés. La première était islamique: il était admis que le savoir devait être transmis au fil des lignées. Ce qui déplaisait à Ali Emiri n'était pas tant l'usurpation du nom que l'irrespect des lois de la transmission. Il fallait dénoncer la supercherie du promu: le faiseur de nom était un faiseur. Il manquait déjà à l'autodidacte la reconnaissance du diplôme. Et quoi! il s'imaginait qu'un pedigree, faux qui plus est, vaudrait licence d'enseigner (icazetnâme). Tout le scandale était là, dans cette récupération des dividendes d'un prestige certes de lignée, mais cultivé au sein d'un système politique exclusif du principe de noblesse, comme droit d'accès héréditaire aux fonctions publiques (memuriyet). Nous touchons là à une deuxième conception, ottomane celle-ci, ardemment défendue par le lettré: il n'était de lignée politique que la lignée d'Osman, il n'était de succession de droit qu'au sein de celle-ci. Il en est une troisième qui régit la sociologie politique de la famille sous les derniers Ottomans.

99. Ahmed Cemal Köprülü était un proche cousin de Fuad Köprülü. Ils ont fréquenté les mêmes écoles, ont effectué des travaux scientifiques ensemble, et se sont engagés dans des activités politiques communes. Le premier rend hommage au second dans «Fuad Köprülü’nün ilmî şahsiyeti, Türk kültüründe rölü ve ba'zı hâtıralar», Türk Kültürü, 7/81, 1969, p. 47-64 [non consulté]. Voir également F. TANSEL, "Ahmed Cemal Köprülü...", art. cit.

100. On lui doit notamment la troisième édition de Türk edebiyatında ilk mutasavvıflar, Ankara, Diyanet İşleri Başkanlı̆̆ı Yayınları, 1976.

101. Orhan F. KÖPRÜLÜ, "Hüseyin Paşa, amcazâde», İslam Ansiklopedisi, 5-1, 1988, Istanbul, Eğitim Bakanlığı Basımevi, p. 646-650. 
Dans toute cette affaire, Ali Emiri pose la question de la nature de la sülale comme lignée patrilinéaire. Il ne pose pas la question de ce qui fonde l'appartenance à la famille. Les historiens du $\mathrm{XX}^{\mathrm{e}}$ siècle qui se sont penchés sur le cas des Köprüluzâde ne le font pas davantage; à les lire, on croirait que, de l'ancêtre éponyme jusqu'à la fondation de la République, les membres du lignage étaient liés à un même groupe. Pour ma part, je fais l'hypothèse qu'entre le début et le milieu du XVIII ${ }^{\mathrm{e}}$ siècle, ce groupe changea de nature. Au temps de leur puissance, les Köprülüzâde, flanqués de leurs alliés Kıblelizâde et Amcazâde, formaient une même maison (household ou hanedan) structurée par de profondes solidarités politiques et patrimoniales. Quelques décennies plus tard, ils s'en étaient séparés. Les lignées gardaient sans doute des intérêts convergents par endroits; une même parentèle incluait des collatéraux. Mais les descendants se rattachaient à des ancêtres différents. Le nom Köprülü était devenu un "classificateur de lignée». Comme aucune noblesse n'était reconnue, il ne cristallisait aucune conscience de la propriété du nom, que des descendants en ligne directe eurent cherché à défendre. Voilà pourquoi les Kiblelizâde n'hésitèrent pas à faire, sur lui, main basse.

Aujourd'hui, les Kıbleli sont tombés dans l'oubli. Les Köprülü sont restés célèbres. Et si les publications sur les grandes familles continuent à ce train, leur nom promet de l'être plus encore chaque jour. Qu'ils se disent ou non descendants du grand vizir, qu'ils aient conservé ou non des documents qui établiraient leur lignée, les Köprülü disposent de toutes sortes de mise en scène de soi par le nom, simple support de l'inter-reconnaissance, mode plus ou moins affiché de distinction sociale, ou goût plus discret pour la «dénégation ${ }^{102}$. Mais ils sont si nombreux qu'il y a fort à parier que la plupart d'entre eux n'accordent pas plus d'importance à leur rattachement au grand vizir que les Racine, pourtant installés à la Ferté-Milon, ne se soucient de leur lien avec le célèbre dramaturge ${ }^{103}$. Leur nom, pourtant, n'a plus le même statut: il a fait l'objet d'un anoblissement républicain; il est durablement associé à la figure du professeur autant qu'à celle du grand vizir. Et qu'importe le lien qui unit le premier au second. Le fait est que, paradoxalement, en République, Mehmed Fuad Köprülü est parvenu à recueillir les fruits de l'opération d'«ennoblissement» initiée par ses ancêtres Kibleli. Il en est ainsi parce que la conception de famille, telle qu'elle s'est dessinée dans la Turquie républicaine, dépasse largement les cadres de l'imaginaire patrilinéaire des lignées ottomanes. Il en est ainsi parce que le nom est loin d'être une simple affaire de famille.

En tant que Köprülü, la figure de Mehmed Fuad incarne tout ce qui compte aux yeux du régime actuel: par ses origines, par sa biographie, et par sa carrière, il est, tout à la fois, l'exemple d'une transition de l'Empire à la République qui

102. Pierre Bourdieu, La noblesse d'État. Grandes écoles et esprit de corps, Paris, Minuit, 1989, p. 548-559.

103. Sur la postérité du nom Racine, voir l'enquête d'Arnaud CHAFFAnjon, Essai sur la descendance de Fean Racine, Paris, Extraits des cahiers raciniens, 1963, p. 50. 
se veut désormais réussie - c'est l'effet de la reprogrammation engagée par le parti islamique au pouvoir depuis 2002 -, d'une capacité à tirer d'un savoir longtemps accumulé une compétence institutionnelle profitable à l'édification d'une université moderne, et d'une intégration, académique puis diplomatique, à l'ordre international des prestiges et des rangs. Que celui-ci soit ou non un Köprülü, qu'importe? Par la loi de 1934, la République a accordé un quitus inaltérable au professeur. Ce Köprülü mérite son épitaphe. Par lui et au-delà de lui, Köprülü est un joli nom d'emprunt de la Turquie à son passé ottoman, un nom qui laisse grand ouvertes les portes de l'imaginaire national.

Olivier BOUQUET SEDET. Sociétés en Développement. Études Transdisciplinaires Université Paris Diderot-Paris 7

Case courrier 7017 75205 PARIS CEDEX 13 olivier.bouquet@gmail.com 


\section{Résumé / Abstract}

Olivier BOUQUET

\section{Onomasticon Ottomanicum III: Köprülü, un assez joli nom d'emprunt}

Mehmed Fuad Köprülü (1890-1966) fut l'historien turc le plus important du XX ${ }^{\mathrm{e}}$ siècle. Il portait le nom de famille de celui qui fut généralement présenté comme son ancêtre, le dignitaire Mehmed Köprülü Pacha, fondateur d'une lignée ottomane qui compta six grands vizirs entre la seconde moitié du XVII ${ }^{\mathrm{e}}$ siècle et les premières décennies du XVIII ${ }^{\mathrm{e}}$ siècle. C'est ainsi qu'il fut désigné avant et après la loi de 1934 qui imposa l'obligation du nom de famille pour l'ensemble des citoyens turcs. Pourtant, en 1918, un historien érudit, Ali Emiri, avait accusé l'universitaire d'avoir usurpé un nom au motif que ses ancêtres directs n'étaient pas les Köprülü mais d'autres dignitaires, les Kibleli.

L'objectif de cet article vise à examiner les fondements et la validité de cette accusation d'usurpation au regard des logiques de l'anthroponymie ottomane. Il rappelle que les noms propres n'étaient pas des désignateurs rigides et que les patronymes changeaient généralement d'une génération à l'autre, en sorte que les lignées distinguées par le service du sultan ne songeaient guère à défendre la gloire d'un nom contre usurpateurs de lignage et falsificateurs de généalogie. Que Mehmed Fuad Köprülü ait été soupçonné d'avoir usurpé un nom, qui n'avait fait l'objet d'aucune défense dans l'Empire de ses ancêtres, est un premier paradoxe qu'il faut éclairer. Il en est un second qui a trait à l'application de la loi de 1934. Fixateur anthroponymique officiel à l'usage des citoyens turcs dans leur ensemble, cette loi fit passer à la trappe de nombreux noms impériaux. Mais elle valida l'usage multiséculaire du nom Köprülü, répandu hors de la seule lignée des grands vizirs, au point qu'aucun de ceux qui le portaient ne semblait y attacher aucun prix ou n'en tirer aucune fierté. Comment donc expliquer qu'un demi-siècle plus tard, ce nom de famille fut davantage associé aux prestigieux grands vizirs au point de cristalliser, dans un régime républicain, une idéologie nobiliaire dont avaient été exempts l'Empire ottoman finissant et la Turquie kémaliste?

MoTS-CLÉS: $\mathrm{XX}^{\mathrm{e}}$ siècle, Turquie républicaine, Empire ottoman, anthroponymie, usurpation, noblesse

\section{Olivier BOUQUET}

\section{Onomasticon Ottomanicum III: Köprülü, quite a nice alias}

Mehmed Fuad Köprülü (1890-1966) was the most important Turkish historian of the last Century. The family name he bore related him to his so-called ancestor Mehmed Köprülü Pasha, an Ottoman dignitary who was at the origin of an illustrious household that-over the length of the imperial periodcounted no less than six Grand Viziers. Mehmed Fuad Köprülü's name was officially ratified by the 1934 Republican Law that made it compulsory for every Turkish citizen to bear a family name. Surprisingly enough, a famous erudite Ali Emiri made harsh accusations against Köprülü, saying he was in fact the descendant of the Kibleli family and calling him an usurper for having borrowed his name from the Köprülü lineage with whom he had no direct relation.

First, the article examines the arguments and validity of the aforementioned accusations put forward by Ali Emiri in light of the anthroponomical Ottoman system. It specifically underlines to what extent proper names generally stemmed from multiple and variable logics of designation in ways that resembled family name changes from one generation to another. As a result, imperial dynasties are considered to have been neither willing to transmit nor defend their names against usurpers who might seek to falsify their own genealogies. Second, the article emphasizes that Köprïlü, as a family name, was associated neither with any kind of official nobility within the imperial political system nor within the context of Kemalist ideology. In doing so, the article addresses the fact that, paradoxically, the name Köprülü became associated with a distinctive elite identity in Republican Turkey, a country shaped by an official meritocratic ideology.

KEYWORDS: $20^{\text {th }}$ century, Republican Turkey, Ottoman Empire, anthroponomy, usurpation, nobility 